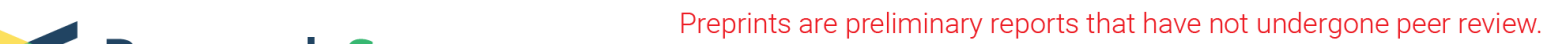 $\begin{array}{ll}\text { Research Square } & \text { They should not be considered conclusive, used to inform clinical practice, } \\ \text { or referenced by the media as validated information. }\end{array}$
}

\section{miR-218 Affects the ECM Composition and Cell Biomechanical Properties of Glioblastoma Cells}

\section{Małgorzata Grabowska}

Institute of Bioorganic Chemistry Polish Academy of Sciences: Instytut Chemii Bioorganicznej Polskiej Akademii Nauk

\section{Konrad Kuczyński}

Institute of Bioorganic Chemistry Polish Academy of Sciences: Instytut Chemii Bioorganicznej Polskiej Akademii Nauk

\section{Monika Piwecka}

Institute of Bioorganic Chemistry Polish Academy of Sciences: Instytut Chemii Bioorganicznej Polskiej Akademii Nauk

\section{Alicja Rabiasz}

Institute of Human Genetics Polish Academy of Sciences

Joanna Zemła

Polska Akademia Nauk Instytut Fizyki Jadrowej im Henryka Niewodniczanskiego

\section{Paweł Głodowicz}

Institute of Bioorganic Chemistry Polish Academy of Sciences: Instytut Chemii Bioorganicznej Polskiej Akademii Nauk

\section{Dariusz Wawrzyniak}

Institute of Bioorganic Chemistry Polish Academy of Sciences: Instytut Chemii Bioorganicznej Polskiej Akademii Nauk

\section{Małgorzata Lekka}

Polska Akademia Nauk Instytut Fizyki Jadrowej im Henryka Niewodniczanskiego

\section{Katarzyna Rolle ( $\sim$ kbug@ibch.poznan.pl)}

Institute of Bioorganic Chemistry Polish Academy of Sciences: Instytut Chemii Bioorganicznej Polskiej Akademii Nauk

\section{Research}

Keywords: glioblastoma, tenascin-C, syndecan-2, miR-218, extracellular matrix, cell migration, cell adhesion

Posted Date: January 5th, 2021

DOl: https://doi.org/10.21203/rs.3.rs-138429/v1 
License: (c) (i) This work is licensed under a Creative Commons Attribution 4.0 International License. Read Full License 


\section{Abstract}

\section{Background}

Glioblastoma (GBM) is the most common malignant brain tumour. GBM cells have ability to infiltrate into the surrounding brain tissue, which results in a significant decrease in the patient's survival rate. Infiltration is a consequence of the low adhesion and high migration of the tumour cells, two features being associated with the highly remodelled extracellular matrix (ECM).

\section{Methods}

The expression profile of miRNAs and mRNAs was analysed by qPCR on 19 GBM tissue samples. Than luciferase assay was performed to confirm interaction between miR-218 and target sequences. Next we checked how supplementation of glioma cell line (U118-MG) with microRNA 218 will change expression pattern of TN-C and SDC both on transcript level and on protein level. Analysis of protein level were made with western-blot technique. Last step in expression profiling of genes connected to cellular motility and adhesion was done with use of qPCR analysis after supplementation with miR-218. To assess the abilities of cells to migrate and proliferate real-time cell culture analysis with use of Incelligence system were utilized. Also this results were backed by classic wound-healing assay. To conclude we used atomic force microscopy (AFM) to measure physical properties such as adhesion and stiffness of cells. This study was supported by microscopy analysis of cytoskeleton changes after supplementation of miR-218.

Results

In this study, we report that ECM composition is partially regulated at the posttranscriptional level by miRNA. Particularly, we show that miR-218, a well-known miRNA suppressor, is involved in direct regulation of ECM components, tenascin-C (TN-C) and syndecan-2 (SDC-2). We demonstrated that the overexpression of miR-218 reduces the mRNA and protein expression levels of TN-C and SDC-2, and subsequently influences biomechanical properties of GBM cells. Atomic force microscopy (AFM) and real-time migration analysis revealed that miR-218 overexpression impairs the migration potential and enhances the adhesive properties of cells. AFM analysis followed by F-actin staining demonstrated that expression level of miR-218 has an impact on cell stiffness and cytoskeletal reorganization. Global gene expression analysis showed deregulation of a number of genes involved in tumour cell motility and adhesion or ECM remodelling upon miR-218 treatment, suggesting further indirect interactions between the cells and ECM.

\section{Conclusion}

The results demonstrated a direct impact of miR-218 reduction in GBM tumours on the qualitative ECM content, leading to changes in the rigidity of the ECM and GBM cells being conducive to increased invasiveness of GBM. 


\section{Background}

Glioblastoma (GBM) is the most malignant astrocytic brain tumour. Despite treatment with state-of-theart therapies, including aggressive surgical intervention, radiotherapy, and systemic chemotherapy, as well as significant advances in the field of oncology, the average survival time for GBM patients is approximately 15 months, with a 5-year survival rate of only $5 \%[1,2]$. The main factor contributing to this poor prognosis is the ability of GBM cells to infiltrate adjacent tissues, resulting in a high rate of tumour recurrence [3]. These notable migration and invasion abilities could be explained by alterations occurring in the structure of cancer cells and their surroundings, defined by mechanobiology [4].

To promote the invasiveness, cancer cells modify their environment, namely the extracellular matrix (ECM). It consists of over 300 different proteins, including proteoglycans, and glycoproteins [5]. Neoplastic tissues are characterized by the phenomenon of desmoplasia, manifested by the intense formation of a dense ECM consisting of increased levels of total fibrillar collagen, fibronectin, proteoglycans, and tenascin-C (TN-C) [6]. The capability to synthesize specific and cancer-related ECM components has been shown to be relevant for the high invasiveness of tumour cells. The changed protein profile within ECM increases the stiffness of cancerous tissue [7,8], which may lead to enhanced cell-ECM adhesion through the involvement of local adhesion proteins. The general trend observed for many types of cells indicates that cell spread and adhesion are improved on harder matrices $[9,10]$. The effect of the environment on the cells is explained by the mechanotransduction mechanism, in which mechanical and cell-specific signals are actively detected by cells and converted into intracellular biochemical signals. In this manner, the ECM can affect cancer cell behaviour, including invasion and metastasis $[11,12]$. Therefore, cancer should be considered a disease with alterations in both cells and their microenvironment, including also the biochemical and biophysical properties of the ECM. Not only proteins suspended in the ECM have an impact on the invasiveness of the tumour, but also transmembrane proteins.. The syndecans are a four-member family of evolutionarily conserved small type I transmembrane proteoglycans implicated in the formation of specialized membrane domains, cell adhesion, cytoskeletal organization, migration, and wound healing. They have been also with pathological conditions, including inflammation and cancer [13-15]. For instance, elevated expression of syndecan-2 (SDC-2) has been correlated with increased invasiveness in various types of cancers, including fibrosarcoma [16], melanoma [17], colon [18], pancreatic [19], and colorectal [20] cancers, while $\mathrm{TN}-\mathrm{C}$ is overexpressed in brain tumours [21] and breast [22], lung [23] and colorectal [24] cancers.

In the recent 20 years microRNAs (miRNAs) have emerged as key regulators of gene expression at the posttranscriptional level. miRNAs are a large family of endogenous, evolutionarily conserved, noncoding RNAs that are $\sim 22$ nucleotides long, and they have been implicated in the regulation of nearly every biological process [25]. Deregulated miRNA expression has been shown to play a role in the pathogenesis of a growing list of human diseases, including cancer and cardiovascular, neurodegenerative and autoimmune disorders [26-29]. For example, in GBM, it has already been demonstrated that downregulation of miR-218 influences cell proliferation, epithelial-to-mesenchymal transition [30]; metabolism of cancer cells [31]; and cancer stem cell properties [32]. How miRNAs are involved in the 
regulation of ECM composition and the mechanobiology of cancer cells in GBM tumours, is largely unknown. In principal, miRNAs can exert their control over the ECM either directly by targeting mRNAs encoding ECM proteins, or indirectly, by modulating the expression of genes involved in the synthesis or degradation of ECM molecules. Here, we have evidenced that miR-218, one of highly downregulated miRNAs in GBM cells, is involved in the direct regulation of TN-C and SDC-2, two highly overrepresented proteins in GBM and ECM components. Both SDC-2 and TN-C have been previously demonstrated to increase tumour cell migration and invasiveness. In the course of the study, we attempted to validate how miR-218 interaction with its ECM targets affects globally a microenvironment and biomechanical properties of GBM cells We introduced miR-218 mimic into GBM cells and measured the consequences on the migration, adhesion and stiffness properties of individual cancer cells. As demonstrated by realtime migration analysis and single-cell force spectroscopy (SCFS) measurements using contact-mode atomic force microscopy (AFM), overexpression of miR-218 had a pronounced effect on the mechanical properties of GBM cells, influencing their migration potential, adhesion and overall stiffness. Collectively, our results indicate that miR-218 is a potent tumour suppressor in glioma with a substantial impact on the ECM composition and biomechanical properties of GBM. More broadly, we conclude that miRNAs can constitute a broad drug target space for modulation of tumour cell's mechanical properties.

\section{Materials And Methods}

\section{Patient samples collection}

The GBM samples $(n=19)$ were obtained from the Clinic of Neurosurgery and Neurotraumatology, Karol Marcinkowski University of Medical Sciences in Poznan, Poland during 2016-2017 based on the the approval from the Ethical Committee (Nr. 46/13) and individuals signed informed consents.

\section{Cell culture}

Human glioblastoma cell line U-118 MG purchased from American Type Culture Collection (ATCC) was used in the study. Cells were maintained in a Dulbecco's Modified Eagle Medium (DMEM, Gibco) medium supplemented with $10 \%$ fetal bovine serum (FBS, Sigma-Aldrich) and $1 \%$ penicillin-streptomycin antibiotic (Sigma-Aldrich) and incubated at $37^{\circ} \mathrm{C}$ and $5 \% \mathrm{CO}_{2}$ in a humidified atmosphere in an incubator.

\section{Transfection}

The cells were transfected with mirVana ${ }^{\mathrm{TM}}$ hsa-miR-218-5p mimic (Invitrogen) in final concentration of $10 \mathrm{nM}$ and $50 \mathrm{nM}$ at $70-80 \%$ confluency Lipofectamine ${ }^{\mathrm{TM}} 2000$ (Invitrogen) was used as a transfection agent according to the manufacturer's protocols. A nonspecific scrambled siRNA (Sigma Aldrich) was used as a control. The cells were processed after $24 \mathrm{hrs}$ for the quantification of transcript levels using qPCR, Western blot, performing the cellular assays or AFM analysis.

\section{Luciferase reporter assay}


The Targetscan (www.targetscan.org) analysis predicted the 3'UTR segments of TN-C and SDC-2 interacting with has-miR-218-5p. Based on them 22 nucleotides long fragments were designed, along with corresponding to them mutants, characterized by one point mutation and one codon change. As a control was used a perfect match sequence, fully complementary to the miR-218. Oligonucleotides were synthesized by Sigma-Aldrich. Fragments were then ligated with the pmirGLO Dual-Luciferase miRNA Target Expression Vector (Promega), transformed by heat shock into TOP10 Escherichia coli cells, and multiplied. Verified by sequencing plasmids were transfected together with mirVana ${ }^{\mathrm{TM}}$ hsa-miR-218-5p mimic to the U-118 glioblastoma cell line. Luciferase activity was analyzed with Dual-Glo $\AA$ Luciferase Assay System (Promega) by the manufacturer's instructions using the Synergy ${ }^{\text {TM }}$ HTX Multi-Mode Microplate Reader (BioTek).

\section{Western blots}

$\mathrm{U}-118 \mathrm{MG}$ cells were lysed by sonication for protein isolation in $10 \mathrm{nM}$ Tris-HCl, $\mathrm{pH}=7$. Protein expression glyceraldehyde 3-phosphate dehydrogenase (GAPDH) level was used as an endogenous control. For TNC, SDC-2 and GAPDH detection, respectively $100 \mu \mathrm{g}, 50 \mu \mathrm{g}$ and $5 \mu \mathrm{g}$ of isolated material was used. Protein was denatured, separated by SDS-PAGE (SDS-polyacrylamide gel electrophoresis) on $12 \%$ gels, with electric current $30 \mathrm{~mA}$ and wet transferred to the polyvinylidene fluoride membrane using electric current $130 \mathrm{~mA}$, blocked with $5 \%$ skimmed milk. After incubation with primary and secondary antibodies proteins of interest were detected with Western Bright Sirius Chemiluminescent Detection Kit (Advansta). The following antibodies in dilution 1:500 were used: polyclonal TN-C H-300 (Santa Cruz Biotechnology), monoclonal SDC-2 67088-1-Ig (Proteintech), monoclonal GAPDH 0411 (Santa Cruz Biotechnology), and in dilution 1:10,000 anti-mouse A9044/rabbit A6154 - peroxidase (Sigma-Aldrich). Antibodies were diluted in $3 \%$ bovine serum albumin (BSA, Sigma-Aldrich). The intensity of individual bands was analyzed quantitively by Multi Gauge ver. 2.0 (Fujifilm). The relative ratio of protein level expression ratio was determined based on the densitometric measurements of band intensities in relation to the control sample.

\section{qRT-PCR}

Total RNA was isolated from U118-MG cell line using the TRIzol reagent (Invitrogen) according to manufacturer's protocol. Afterwards, RNA was purified with the DNA-free ${ }^{\text {TM }}$ DNA Removal Kit (Ambion). The reverse transcription reaction was carried out with the Transcriptor High Fidelity cDNA Synthesis Kit (Roche) according to the manufacturer protocol, using in each case $500 \mathrm{ng}$ of RNA material. The reverse transcription for miRNA was performed by two step miRNA 1st-Strand cDNA Synthesis Kit (Agilent Technologies). cDNA was used in real time quantitative reverse transcription PCR (qRT-PCR), with use of LightCycler®480 (Roche), in three technical replicates. Primers with corresponding probes were designed in the Universal Probe Library Assay Design Center (https://qpcr.probefinder.com/organism.jsp). Relative expression was analyzed in the LightCycler®480 Software release 1.5.1.62 (Roche). The level of hypoxanthine phosphoribosyltransferase (HPRT) was used as an endogenous control for analysis of extracellular matrix proteins. In case of miR-218 the level of 18S ribosomal rRNA was used for normalization. Sequences of primers 5'-3' and list of probes: TN-C forward: 
GGGATTAATGTCGGAAATGGT; TN-C reverse: CCGGACCAAAACCATCAGT; TN-C probe: 76; SDC-2 forward: TTATCAGATGTCAGCTCTGCTCTC; SDC-2 reverse: GTGGATCCTGCTCACCTTG; SDC-2 probe: 49; HPRT forward: CGAGCAAGACGTTCAGTCCT; HPRT reverse: TGACCTTGATTTATTTTGCATACC; HPRT probe: 73; miR-218: TTGTGCTTGATCTAACCATGT; R18 forward: CATTCTTGGCAAATGCTTTCG; R18 reverse: CGCCGCTAGAGGTGAAATTC.

As a control RNA from normal, healthy brains (Ambion, First Choice ${ }^{\circledR}$ Human Brain Reference RNA (Cat \# 6050, whole brain pooled from 10 females and 13 men, Caucasian, age: 23-86) was used.

\section{PCR Array of human cell motility, extracellular matrix, and adhesion molecules}

Cells were collected for total RNA isolation with ExtractME Total RNA Kit (Blirt) according to manufacturer's protocol. $900 \mathrm{ng}$ of RNA was used in reverse transcription procedure with RT ${ }^{2}$ Easy First Strand kit (Qiagen). cDNA mixed with the $\mathrm{RT}^{2}$ SYBR Green were then evenly aliquoted onto the $\mathrm{RT}^{2}$ profiler plates: Human Cell Motility, and Human Extracellular Matrix and Adhesion Molecules (Qiagen). qRT-PCR reactions were conducted in LightCycler ${ }^{\circledR} 480$ (Roche), subsequently analyzed by software provided online by Qiagen.

\section{Real-time migration}

Real-time cell migration monitoring was performed in the $\mathrm{xCELLigence}{ }^{\circledR}$ system using the RTCA DP apparatus (ACEA Biosciences). The experiment were carried out on 16-well CIM-Plates, in which culture medium enriched with FBS, served as a chemoattractant, was applied into lower part of the CIM-Plate. To the upper chamber was applied an un-supplemented medium. The first stage of the experiment served to measure the background of electrical impedance. Then, 10,000 cells were seeded on the upper chamber of the plate. CIM-Plate was installed in the RTCA apparatus from that moment, for further 48 hours, the system registered the level of electrical impedance every 15 minutes. The results of the experiment were presented in the cell index unit of the XCELLigence ${ }^{\circledR}$ system, which corresponded to the measured impedance minus the impedance of the background. The proper analysis assumed the adjustment of the curves obtained in the experiment to the sigmoidal equation and determining on it the half-time effective migration time (effective time 50, ET 50).

\section{Wound healing assay}

Cells were grown to achieve $90 \%$ of confluency on 12-well plates and then transfected. After the medium change, scratches were created by scraping cells in a straight line using a $200 \mu \mathrm{l}$ tip. From that moment on, for 72 hours at 12-hour intervals, pictures of the culture were taken by a Leica DMI4000 B inverted microscope with $5 x$ magnification objective. The analysis of the degree of the individual scratch area was carried out by the Tscratch software version 1.0 (CSElab).

\section{Real-time proliferation}


The use of the $x C E L L i g e n c e \circledast$ system enabled the observation of real-time cell proliferation. In that experiment were used the E-Plates (Acea Biosciences), whose wells bottoms are covered with gold microelectrodes. The test was started by measuring the background impedance of supplemented medium by placing them in the RTCA DP apparatus (ACEA Biosciences) and making the first measurement. Then, 10,000 cells were seeded on the same plate and incubated 24 -hour under optimal growth conditions. From that moment on, until the end of the experiment, the system performed impedance measurements at 15-minute intervals. After 24 hours, the cells were transfected, and measurements were continued for the next 48 hours. The results are presented by the cell index unit. Normalization time point corresponds to the moment of transfection.

\section{Thymidine incorporation assay}

The cell culture was transfected and resumed for 20 hours. Subsequently a tritiated thymidine ([methyl-3 $\mathrm{H}]$-thymidine) labeled solution with final radioactivity of $1 \mu \mathrm{Ci}$ per well was added for another four hours. To detach the cells, they were placed for $30 \mathrm{~min}$ at $-80^{\circ} \mathrm{C}$ and then thawed at $37^{\circ} \mathrm{C}$. The plate was placed in the MicroBeta FilterMate-96 harvester, where the cells were transferred to the fiberglass filter paper Filtermat A (PerkinElmer) by three washes. Dried Filtermat A was placed in the plastic sample bags, and flooded with Betaplate Scint for Betaplete (PerkinElmer), then moved into the MicroBeta ${ }^{2}$ radiometric detector (PerkinElmer), which recorded the number of radioactive pulses per minute (counts per minute, $\mathrm{cpm})$. As a positive control cells treated with camptothecin (CPT) at a final concentration of $3 \mu \mathrm{M}$ were used.

\section{Real-time adhesion}

The xCELLigence ${ }^{\circledR}$ system together with The E-Plates PET (Acea Biosciences) was used. In each well of them, four rows of microelectrode sensors are removed, creating a window for cells visualization. Plates were covered with poly-L-lysine, incubated for one hour in 37囚C and rinsed with phosphate buffered saline (PBS, VWR Life Science). Additionally, some wells were overlaid with $1 \%$ BSA for 20 min and acted as a negative control. An un-supplemented medium was analyzed as a background. Then 24 hours earlier transfected cells were seeded 10,000 per well in serum-free medium. Measurements took place every three minutes for four hours.

\section{Single Cell Force Spectroscopy (SCFS)}

Cell deformability and adhesiveness were determined from the AFM measurements carried out in single cell force spectroscopy (SCFS) mode using CellHesion head (JPK Instruments). In SCFS, adhesion was quantified as a work of adhesion determined as an area under the part of the force curve corresponded to force/work needed to detach a single cell from surface [33,34] To prepare a cell force probe, the standard tipless cantilevers (Arrow-TL, NanoWorld) characterized by nominal spring constant of $0.06 \mathrm{~N} / \mathrm{m}$ were used. Average spring constant was $0.067 \pm 0.016 \mathrm{~N} / \mathrm{m}$, as verified by Sader method (Sader et al. 1995). First, bare cantilevers were cleaned and activated with an oxygen plasma for 2 minutes at the maximum power of $100 \mathrm{~W}$ (Diener Elecronics $\mathrm{GmbH}$, Zepto 1 device). Afterwards, cantilevers were immersed in $2 \mathrm{mg} / \mathrm{ml}$ concanavalin A (Con A, Sigma-Aldrich) solution in PBS buffer (Sigma-Aldrich) for 1 hour and 
washed three times in PBS buffer. To use an individual cell as a force probe, the trypsinized solution of transfected cells was added to Petri dish (diameter $3.5 \mathrm{~cm}$, Sarstedt) filled with DMEM with FBS, in which SCFS measurements were performed. Then, Con A functionalized cantilever was placed above a single cell and moved closer to its surface, followed by pressing it for about $5 \mathrm{~s}$ with the force of $5 \mathrm{nN}$.

Afterwards, a slow cantilever withdrawing was applied until the cell fully detached from the surface. After 15-20 min of a pause time, the cell was usually attached to the cantilever surface. From this moment, the cell was used as a probe to collect force curves. For a single force probe on average 5 force maps (scan size of $20 \mu \mathrm{m} \times 20 \mu \mathrm{m}$, on which a grid 6 pixels $\times 6$ pixels was set) were recorded in randomly chosen locations on Petri dish surface. For a given sample type, 9-11 living cell force probes were used. In total for each sample type, on average 1800 individual force curves were recorded and analyzed. The approach and retract speeds were kept at $8 \mu \mathrm{m} / \mathrm{s}$. The measurement depth was $200 \mathrm{~nm}$. From the approach part of the force curve, cell stiffness $(\mathrm{N} / \mathrm{m})$ was determined by fitting a line to a sloped part of the curve after a contact with a cell surface. In parallel, from the retract part of the force curve, work of adhesion was calculated as an area under this part of force curves corresponding to adhesion using methodology described elsewhere [33,34].

\section{Cytoskeleton imaging}

For structural cytoskeleton analysis, U-118 MG cells were cultured on microscope coverslips and transfected under standard conditions as described previously. 24 hours post-transfection cells were fixed with use of Image-iT ${ }^{T M}$ Fixation/Permeabilization Kit (Invitrogen) accordingly to manufacturer protocol. Factin fibers were visualized by phalloidin conjugated to tetramethylrhodamine (Invitrogen) with simultaneous use of DAPI (Sigma Aldrich) to visualize cells nuclei. Staining was performed accordingly to manufacturer protocol. Pictures were obtained with use of Leica TCS SP5 confocal microscope and software LAS X SP8 (Leica).

\section{Statistical analysis}

The results are presented as a mean value \pm standard deviation (SD). They were averaged depending on the applied methods. For AFM measurements, averaging was performed for 9-10 cell force probes. For other experiments 3 biological replicates were applied. Statistical significance of the obtained results was evaluated using the Open Office Calc ver. 4.1.1 (Apache) and GraphPad Prism ver. 5.1 (GraphPad Software). Differences between the mean values of the test and the control samples were evaluated using ANOVA variance extended by Tukey or Bonferroni post hoc tests. Statistically significant results were assigned as: * for $p<0.05$; $* \star$ for $p<0.01$; $* \star \star$ for $p<0.001$; no statistical significance for $p \geq 0.05$.

\section{Results}

In glioblastoma, the expression level of miR-218 correlates inversely with the expression levels of the ECM components TN-C and SDC-2

Our previous study revealed 97 miRNAs differentially expressed in glioblastoma compared to the healthy brain [33]. Forty-one of these miRNAs showed a reduced expression level in malignant gliomas. Among 
these miRNAs, we found miR-218 to be significantly downregulated in brain tumour tissues. We further confirmed the expression level of miR-218 in primary and recurrent GBM via qRT-PCR analysis (Fig. 1). The levels of miR-218 expression in primary tumour tissue and recurrent GBM tissue were $56 \%$ and $69 \%$ lower, respectively, than those in healthy brain tissue.

Given the profound downregulation of miR-218 in GBM, we sought to investigate its putative targets. To identify the binding sites in the 3'UTRs of genes that can be potentially regulated by selected miRNAs, we used prediction software such as MiRanda, TargetScan, PicTar, and miRWalk. Interestingly, among the predicted targets, we found several genes encoding ECM proteins, such as tenascin-C ( $T N-C)$, syndecan-2 (SDC-2), attractin ( $A T R M)$, cadherin-2 (CDH-2), plexin-A4 (PLXN-A4) and metalloproteinase-24 (MMP-24) (Fig. 1b).

\section{TN-C and SDC-2 are direct targets of miR-218}

Highly ranked binding targets of miR-218 were subjected to further analysis. We focused specifically on $T N-C$ and $S D C-2$ and investigated their gene expression levels via qRT-PCR. The tenascin-C level was significantly increased in all examined tumour samples-i.e., 8-fold higher in primary tumour tissue and 21 -fold higher in recurrent tumour tissue than in healthy brain tissue. In the case of $S D C 2$, our analysis indicated an increase of approximately 4-fold in GBM (Fig. 1c).

All algorithms used for miR-218 target prediction showed one binding site within the $3^{\prime} \mathrm{UTR}$ of both the $T N-C$ and $S D C-2$ mRNAs. We employed a set of reporter constructs in a luciferase assay to experimentally verify the predicted binding of miR-218 to its target sites within the 3' UTRs of $T N-C$ and SDC-2. The following constructs were tested in parallel: wild-type reporters (WT) containing a single native binding site for either miR-218, constructs with mutations (MUT) disrupting the 5' seed site (negative controls) and constructs with perfect complementarity (PM) to the miR-218 binding site (positive controls) (Fig. 2a). Considering our previous analysis revealing the inverse correlation between miR-218, TN-C and SDC-2 expression, we validated the predicted miRNA-mRNA interactions using a miRNA overexpression system. Specifically, U-118 MG cells were co-transfected with reporter constructs and miRNA-encoding plasmids. Co-transfection experiments showed that cells transfected with miR-218 had significantly inhibited luciferase activity compared to cells transfected with negative control (MUT) miRNA (Fig. 2b). The reduction in luciferase activity was reproducible and statistically significant for both WT constructs, with suppression of $33 \%$ and $74 \%$ for TN-C and SDC-2, respectively. miR-218 did not inhibit the luciferase activity of reporter vectors containing the $T N-C$ and $S D C-23^{\prime} U T R s$ with mutations in the putative miR-218 binding site. This study provides evidence of the direct binding of miR-218 to the TN-C and SDC-2 3'UTRs and positively validates this miRNA as a negative regulator of these ECM molecules.

\section{miR-218 regulates TN-C and SDC-2 protein levels}

We sought to determine the role of miR-218 in the regulation of TN-C and SDC-2 at the protein level in GBM cells by a gain-of-function approach. We transfected U-118 MG cells with synthetic miRNA (miRNA 
mimic) at concentrations of 10 and $50 \mathrm{nM}$. The final miR-218 mimic concentration of $10 \mathrm{nM}$ boosted the expression of miR-218 by almost 500 -fold compared to the control level, while $50 \mathrm{nM}$ increased the expression by more than 5000 -fold (Fig. 2c).

To further verify the function of miR-218 and its impact on TN-C and SDC-2 expression levels, we performed analyses at both the mRNA and protein levels by qRT-PCR and Western blot analysis, respectively. At the mRNA level, transfection with the miR-218 mimic resulted in a reduction in the tenascin-C expression level of $45-52 \%$ in comparison to the control level. In the case of syndecan-2, we observed a decrease of 34-43\% (Fig. 2d). Western blot analysis revealed downregulation of TN-C and SDC-2 expression by $11-47 \%$ and $45-74 \%$, respectively (Fig. 2 e, f).

\section{miR-218 affects the ECM composition}

Given the above results, we sought to determine whether miR-218 overexpression has a broader effect on the ECM composition. To test this hypothesis, we used a Human Cell Motility as well as Extracellular Matrix \& Adhesion Molecules RT ${ }^{2}$ Profiler PCR Array and profiled the expression of $n=160$ genes related to the motility and adhesion pathways. More than $95 \%$ of the transcripts were detected, but expression of CDH1, ANOS1, CNTN1 and MMP8 was not detected by this technique in our analysis (data not shown). Quality control parameters (positive PCR controls and reverse transcription controls) showed good reproducibility and efficiency with the web-based $\mathrm{RT}^{2}$ profiler PCR Array Data Analysis program. In this publication we include results where $p$-value is lover than 0,05 and fold change value is in range $(\infty,-1) \cup$ $(1, \infty)$. Full set of data obtained from $\mathrm{RT}^{2}$ profiler plates is included in supplementary materials (Supplementary Information 1) We identified 47 genes displaying significantly different expression as a result of miR-218 mimic transfection. It became evident from the results that miR-218 overexpression led mostly to decreases in the expression of genes, among which were tenascin-C, as its direct ECM target, as well as the other genes involved in cytoskeletal reorganization. We further hypothesized that changes in the ECM composition due to miR-218 overexpression also affect the mechanobiological properties of cancer cells.

\section{Impaired cell migration after miR-218 treatment}

To explore the impact of miR-218 on cell migration, we compared the migration rate of miR-218transfected U-118 MG cells with that of non-treated (negative control) cells (Fig. 4a). The mathematical interpretation of the impedance ( $\mathrm{Cl}$ value) for each experimental condition was recorded over time and fitted to a four-parameter logistic non-linear regression model (Fig. 4b). Transfection of 10 and $50 \mathrm{nM}$ miR-218 increased the $\mathrm{ET}_{50}$ by an average of 4 and $4.7 \mathrm{~h}$, respectively. These results clearly show a concentration-dependent correlation.

As the second independent experiment, we carried out a wound healing assay. 48 hours after transfection, the largest unhealed area was observed in the miR-218 $50 \mathrm{nM}$ sample and accounted for $25.2 \%$ of the original wound area, while in the control sample, it was $0.8 \%$ (Fig. 4c, d). At a concentration of $10 \mathrm{nM}$, the unhealed area was $2 \%$ of the original wound area. The most pronounced difference in the 
function of miR-218 was revealed at the $24 \mathrm{~h}$ time point, when the wound areas in the control and mimic $10 \mathrm{nM}$ and mimic $50 \mathrm{nM}$ samples were $4.4 \%, 45.3 \%$ and $56.2 \%$, respectively. Both experiments indicated a delay in GBM cell migration rate upon miR-218 treatment.

We analysed real-time cell proliferation with the XCELLigence system. The graph shows the raw experimental data presented as the dependence of the cell index unit used in the xCELLigence system on the time (Fig. 4e). In this way, the time course of proliferation changes with overexpression of miR-218 is illustrated. At the point on the timeline corresponding to $24 \mathrm{~h}$, the curve inflection indicates the time of transfection. The stimulating effects on proliferation are seen at the final points of the curves, $48 \mathrm{~h}$ post transfection. We observed an increase in the cell index by $14 \%$ at a miR-218 mimic concentration of $10 \mathrm{nM}$ and by as much as $19 \%$ at $50 \mathrm{nM}$. This demonstrates the directly proportional relationship between the increase in the proliferation rate and the expression of miR-218.

A [methyl-3H]-thymidine incorporation assay was performed to complement the proliferation analysis with the XCELLigence system. In this study, the degree of incorporation of radioactively labelled thymidine was evaluated and translated into the replication potential of cells. In addition to the standard trials used, we analysed the effect of $3 \mu \mathrm{M}$ camptothecin, which has a confirmed pro-apoptotic effect[34], as a positive control in the experiment. The incorporation rate in CPT-treated cells was $69 \%$ that in control cells. miR-218 mimic transfection increased the incorporation of tritiated thymidine by $57 \%$ at $10 \mathrm{nM}$ and $49 \%$ at $50 \mathrm{nM}$ compared with that in control cells (Fig. 4f).

\section{miR-218 enhances glioma cell adhesion}

To explore the impact of miR-218 on U118-MG cells, the cell surface properties were quantified using AFM in SCFS mode (Fig. 6a). These properties are quantified by calculating the work of adhesion, which is defined as the work required to detach a single cell from the surface. In this scenario, each single cell was used as a force probe. For control cells, the work of adhesion changed from $0.00065 \mathrm{pJ}$ to $0.00216 \mathrm{pJ}$, with a mean \pm standard deviation of $0.0016 \pm 0.0005 \mathrm{pJ}$. The analogous variability in cell adhesion after miR-218 treatment ranged from $0.0019 \mathrm{pJ}$ to $0.0088 \mathrm{pJ}$ (mean \pm standard deviation $=0.0036 \pm 0.0022 \mathrm{pJ}$ ) and from $0.0008 \mathrm{pJ}$ to $0.0096 \mathrm{pJ}$ (mean \pm standard deviation $=0.0034 \pm 0.0024 \mathrm{pJ}$ ) for concentrations of $10 \mathrm{nM}$ and $50 \mathrm{nM}$, respectively. Thus, these results clearly show the overall increase in the adhesive properties of cells after miR-218 overexpression.

Real-time adhesion measurements performed with the XCELLigence system showed changes in the attachment of cells to the plate surface during the observation period (Fig. 6b). The cell index of adhesion for cells treated with $10 \mathrm{nM}$ miR-218 mimic was 2.5 -fold greater than that of control cells. In the case of $50 \mathrm{nM}$ miR-218 treatment, the observed index was 3 times higher than that measured in the control cells. From the beginning of the experiment to its end, the trends in the particular samples did not change. We assumed that the observed changes were miR-218-dependent, since the negative control cells did not bind to the plate covered with BSA. The untreated cells also showed low adherence compared to the miR218-treated cells. 
Thus, regardless of the technique used for the adhesion study, these two independent experiments demonstrated an increase in the adhesion of GBM cells treated with the miR-218 mimic.

\section{Overexpression of miR-218 influences cell stiffness}

Most surface receptors are linked not only to ECM proteins but also to actin filaments forming the actin cortex [35]. Thus, in our next step, we verified whether changes in GBM cell adhesive properties contribute to the overall mechanical properties of these cells. Cell stiffness was measured for cells compressed between the surface and a tipless cantilever; therefore, it was calculated as the slope of the approach part of the recorded force curves and expressed in N/m (Fig. 6a).

For all sample types, i.e., control cells or cells treated either with $10 \mathrm{nM}$ or with $50 \mathrm{nM}$ miR-218, the stiffness of compressed cells remained mildly changed. Here, a smaller variability in mechanical force was observed for a given cellular force probe, as indicated by the standard deviation values. For control cells, the stiffness varied from $0.0022 \mathrm{~N} / \mathrm{m}$ to $0.0097 \mathrm{~N} / \mathrm{m}$ with a mean \pm standard deviation of $0.0065 \pm$ $0.0035 \mathrm{~N} / \mathrm{m}$. Cells treated with miR-218 were characterized by a stiffness ranging from $0.0025 \mathrm{~N} / \mathrm{m}$ to $0.0093 \mathrm{~N} / \mathrm{m}$ (mean \pm standard deviation $=0.0062 \pm 0.0023 \mathrm{~N} / \mathrm{m}$ ) and from $0.0022 \mathrm{~N} / \mathrm{m}$ to $0.0094 \mathrm{~N} / \mathrm{m}$ (mean \pm standard deviation $=0.0067 \pm 0.0020 \mathrm{~N} / \mathrm{m}$ ) for concentrations of $10 \mathrm{nM}$ and $50 \mathrm{nM}$, respectively. Regardless of the final values of cell stiffness, an increasing trend was seen. For cells treated with $10 \mathrm{nM}$ miR-218 mimic, the stiffness was increased by 30\%, and for cells treated with $50 \mathrm{nM}$ miR-218 mimic, the increase was $31 \%$. As the cell stiffness measured using AFM is related to the organization of the actin cytoskeleton, the organization of the actin cytoskeleton was further visualized using fluorescently labelled F-actin to verify the effect (Fig. 6b) Fluorescence images of the actin cortex show differences between control and miR-218-treated cells. Cells treated with miR-218 showed a higher level of actin filament organization. In these cells, the actin filaments became organized more horizontally along the long axis of the cell compared to those in control cells, where they were more dispersed. After treatment with $50 \mathrm{nM}$ miR-218, also small membrane structures appeared at the cell surface. The F-actin dynamics and changes in filament organization directly support the increased stiffness of cells treated with the miR-218 mimic. The observed changes fully confirm the hypothesis that cell stiffness is related to the cytoskeleton.

\section{Discussion}

The malignancy of glioblastoma depends on its ability to infiltrate adjacent tissues and to create secondary lesions [37]. The aggressive growth of glioma tumours and difficulties in developing an effective treatment scheme have led to intense integration of medical and molecular biological research. Remodelling of the ECM and miRNA deregulation are known processes contributing to GBM cell invasion and brain infiltration [38-41]. Here, we validated miR-218 as the functional regulator of ECM remodelling in a glioblastoma cell line. We found that TN-C and SDC-2 were directly regulated by miR-218, resulting in alterations in the ECM composition as well as changes in the mechanical properties of the cells. Our previous finding identified miR-218 as a potential tumour suppressor in brain tumours [33]. The sequence of miR-218 is located within intronic sequences of the SLIT2 and SLIT3 genes, and both of these genes 
are hypermethylated in GBM [42], which could explain its significant downregulation. Indeed, we confirmed that the expression of miR-218 is decreased by $50 \%$ in primary tumours and by $~ 70 \%$ in recurrent GBM tumours. Decreased miR-218-5p expression levels have also been reported in other types of human cancer, such as medulloblastoma, thyroid cancer and cervical cancer [43-45]. We confirmed that the predicted miR-218 targets, the ECM components TN-C and SDC-2, are directly regulated by miR218. We used a dual-luciferase assay and miR-218 mimic to verify these functional interactions. The effects were detectable at both the mRNA and protein levels for both TN-C and SDC-2. Proteins derived from these transcripts are potentially key factors in the ECM of cancer cells [15,21]. The presence of TN-C in cancer tissues was initially considered a characteristic feature of only gliomas [46], with its expression increasing in proportion to the degree of brain tumour malignancy [47]. Its presence was found to increase the proliferation and invasiveness of cancer cells and to take part in the process of angiogenesis [48]. The role of TN-C in the neoplastic process is to reduce the adherence of cells, leading to the spread of the tumour. On the surface of healthy fibroblasts, fibronectin (FN) interacts with transmembrane proteins-integrins and syndecan-4 (SDC-4). The Rho protein is activated, and the properties of actin filaments are changed, resulting in cell adhesion. In pathological conditions, tenascin-C blocks the interaction between FN and SDC-4. The Rho protein is not activated, resulting in a lack of cell adhesion signals [49]. Considering the impact of $\mathrm{TN}-\mathrm{C}$ on cancer cells and its apparent overexpression in glioblastoma tissues, it should be considered an excellent therapeutic target. Treatment with a doublestranded RNA targeting TN-C increased the average survival rate of patients [50].

An increased level of syndecan-2 is a characteristic of actively migrating cells [51]. Overexpression of this protein in melanoma cells indirectly contributes to an increase in the level of FAK kinase phosphorylation, which has a positive impact on the migration capability of these cells [17]. In lung cancer, SDC-2 deficiency prevents cells from adhering to FN, which blocks their migration [52].

ECM has become one of the most important focuses of cancer research, as it was shown to play a major role in the development of metastasis [53]. Pronounced ECM remodelling affects the invasion and migration of cancer cells $[54,55]$. Thus, the major regulator of cell motility is ECM stiffness. The mechanical properties of the ECM have an impact on fibronectin fibril assembly, cytoskeletal stiffness and the strength of integrin-cytoskeleton linkages, the factors found to be important for cell motility, and thus also on adhesive properties [56]. As demonstrated in previous reports, a more rigid ECM promotes glioma cell migration [57]. On highly rigid ECMs, tumour cells spread extensively, form prominent stress fibres and mature focal adhesions, and migrate rapidly [57]. Our results are in line with these observations, as we showed a decreased cell migration rate after mir-218 overexpression, with subsequent downregulation of TN-C expression. These direct effects were enhanced by the indirect effect of miR-218 on a number of proteins, e.g., fibronectin, collagens or laminins. Thus, with miR-218 overexpression, we observed changes in the ECM leading to slowed cell migration, most likely induced by changes in overall ECM rigidity.

Together with the cell volume and cytoskeletal dynamics, the ECM composition is another important parameter that influences the "Go-or-Grow" phenomenon of glioma cells [58]. The "Go-or-Grow" decision 
is strictly regulated and modulated by changes in the tumour microenvironment, which allows cells to "Go" towards more favourable conditions to proliferate at the distant site or to "Grow" if their current environment provides the proper conditions for tumour growth. Changes in miRNA expression can modulate the "Go-or-Grow" decision. Overexpression of miR-451 was shown to be related to shorter survival times of GBM patients and to increased cell proliferation [59]. In contrast, the considerable overexpression of miR-9 in GBM was shown to inhibit proliferation but concurrently promote migration. These results are consistent with our observations, where we found that miR-218 leads to a decrease in the migration rate. In addition, we observed an increase in the proliferation potential (Fig. 4). This finding could then suggest that changes in the ECM properties lead to changes in cell migration behaviour impacted by the more favourable environment promoting cells to stay at the site of origin. There is evidence indicating that mechanical properties and deformability can be used as biomarkers to distinguish between healthy and cancer cells. The deformability of a whole cell, which depends on the properties of the cytoplasm, the cytoskeleton and the nucleus, can be defined in terms of the response of the cell to an applied stress. One of the techniques that enables the measurement of biophysical properties of cells, such as adhesion and stiffness, is AFM [60]. We evaluated the mechanobiological properties of GBM cells, including adhesion and stiffness, upon miR-218 mimic treatment. We obtained real-time measurements in cell culture (xCELLigence system) and measured physical forces and the work of adhesion [61] by application of AFM in SCFS mode. This approach allowed us to quantify the adhesion of single cells. SCFS analysis revealed strengthened adhesion of GBM cells upon miR-218 overexpression, hence indicating the direct connection between miR-218 and ECM component regulation.

GBM cells, similar to other solid cancers, can remodel the surrounding microenvironment from a normal brain to a stiffer tumour microenvironment through the combination of proteolytic degradation of some ECM components and secretion of other novel ECM components [62]. In our analysis, the stiffness of miR-218-transfected cells as measured by AFM was 30\% higher compared to the control cells. Despite the variability observed in the experiment, a clear difference was observed, as the overall stiffness was measured to increase in cells treated with miR-218. The differences observed in the experimental cell group might have stemmed from the distributed contribution of surface receptors on an individual single cell, which can thus impact the adhesion of that cell $[63,64]$. It has already been shown that tumours can become stiffer than normal tissues due to increased Rho-dependent cytoskeletal pressure, generating excessive growth, focal adhesions, adjacent joint division, and tissue disruption [65]. Stiffness also directly depends on the malignancy of the tumour. It is known that invasive GBM tumours produce stiffness-promoting factors such as collagen, fibronectin and laminins, which may suggest that the production of these proteins is disrupted after miR-218 overexpression [66].

An increase in stiffness has also been observed in many different types of cancer cells, such as breast cancer, melanoma, prostate cancer and cervical cancer cells. An important aspect of cell stiffness is the ratio of cancer to normal cells. While cancer cells are less stiff than normal cells [67], the same pattern of stiffness is also observed in malignant versus non-malignant tissues in breast cancer [68], bladder cancer [69] and prostate cancer [70]. In our research, glioblastoma cells with miR-218 overexpression were approximately $30 \%$ stiffer than non-treated cells. Increased stiffness in brain tissues can be correlated 
with diseases such as brain abscess or with cytoskeletal maturation in brain cells [71]. The correlation of cytoskeletal maturation with an increase in cell stiffness has been observed for astrocytes, in which the AFM-measured stiffness may increase sevenfold in a 5-week observation period during development [72]. In miR-218-treated GBM cells, the actin cytoskeleton was slightly rearranged, which could explain the increase in cell stiffness.

The minor discrepancy in the relation between cell surface adhesive properties and cell stiffness measured in our study can be explained by the different scales of measurements. For cell adhesion, SCFS measurements are limited to local changes occurring on the cell surface, while the stiffness reflects the overall mechanical properties of cells. Thus, we analysed stiffness assuming an indentation depth of $200 \mathrm{~nm}$. This value assures the sensing of a superficial layer of actin filaments. Additionally, brain tissue is much softer than other tissues. The value of Young's modulus ranges from 1 to $1,9 \mathrm{kPa}$ for white matter and from 0,8 to $1,4 \mathrm{kPa}$ for grey matter, depending on the measurement technique [73,74]. Independent methods, i.e., SCFS and the XCELLigence system, showed similar increases in the adhesive properties of U-118 MG cells upon miR-218 treatment. Collectively, these results demonstrated that miRNA-218 strongly affects the expression of genes encoding cell surface receptors responsible for the adhesive properties of cells.

We also found that miR-218-treated cells are more rigid than non-treated cells, which most likely prevents them from undergoing extravasation and intravasation during migration and invasion events. We thus hypothesized that miR-218 overexpression supports the maintenance of the normal-like cell phenotype, which is correlated with differences in mechanical properties. The observation is more important when one realizes the importance of ECM rigidity in the perivascular space. It has already been shown that this part of the brain tissue is more rigid in GBM, thus promoting glioma cell migration [57].

miR-218-5p deregulation is involved in GBM growth and migration potential. In addition to the direct influence that miR-218 has on transcripts such as TN-C or SDC-2, as shown in this study, it can influence the ECM composition by targeting other molecules, e.g., the Wnt/ $\beta$-catenin pathway transcription factors LEF1 or MMP-9 [75]. There are data showing that miR-218 suppresses cell invasion and spheroid formation [76], arrests GBM cells in G1 phase [31] and can reduce the expression of cancer stem cell markers such as CD133, SOX2 and Nestin [77]. The complex influence that miR-218 has on GBM cells cannot be underestimated and studied only by evaluating direct targets of this miRNA, therefore in search of indirect targets of miR-218 in glioblastoma, we performed an extended expression analysis and found 47 genes connected to focal adhesion and cell motility. After miR-218 overexpression in glioblastoma cells, we observed a decrease in the expression levels of GBM oncogenes such as PIK3CA, ROCK1, $\angle A M C 1$, and ICAM1. The expression of these genes is increased in GBM compared to healthy tissues [78-81]. Enhanced miR-218 levels also reduced the expression levels of the CRK, RHOA and PTPN1 genes involved in GBM progression [82-84]. Our results are supported by data in the literature indicating a decrease in the expression levels of PIK3CA [85], RHOA [86] and STAT3 [45,87] as a consequence of miR-218 overexpression. 
Due to the nature of our research, the changes in the expression levels of CDC42, STAT3, EGF and CTTN might be particularly important. Previous reports have indicated that $C D C 42$ is a critical determinant of the migratory and invasive phenotype of malignant gliomas $[88,89]$. The STAT3 level is correlated with GBM malignancy, indicating its participation in increasing the migration potential of cancer cells [90]. Additionally, regarding $E G F$, its impact on the migratory nature of GBM cells is known [91]. CTNN and the Arp2/3 complex are known for regulating lamellipodia formation, and a decrease in CTNN expression can suppress GBM migration mechanisms [92,93]. Because we showed a decrease in the migration capacity of glioblastoma cells under treatment with miR-218 in our studies, we can conclude that these changes are the result of the impact of miR-218 on CDC42, STAT3, EGF and CTTN.

The observed increase in GBM cell adhesion may also be associated with a decrease in ACTN1 expression. It has been shown that after downregulation of ACTN1, GBM cells show poor spread but increased focal adhesion [94]. The changes in the cytoskeleton that we observed may be the result of a reduced HGF level, which has been demonstrated to affect the distribution of the actin cytoskeleton in glioblastoma cell lines [95]. Both the cancer migration pathway and deregulation of the actin cytoskeleton can be related to downregulation of SH3PXD2A after miR-218 overexpression. SH3PXD2A is a crucial element in the formation of actin-based invadopodia-protrusions of the plasma membrane that are associated with mechanisms of invasiveness [96,97].

\section{Conclusions}

In this study, we showed that miRNA, as posttranscriptional gene regulator has an direct impact on the ECM composition and, as a consequence, the mechanobiological properties of glioma cells. We demonstrated that miR-218 can be considered a potent tumour suppressor that directly participates in post-transcriptional regulation of the expression of the extracellular matrix proteins tenascin- $\mathrm{C}$ and syndecan-2. The most intriguing observations in this study is the impact of miR-218 on the mechanical properties of the cells, i.e., migration and adhesion, followed by the direct changes of cell stiffness as measured with AFM technology. Additionally, our global gene expression analysis revealed changes in a number of genes directly or indirectly involved in cell motility and thus adhesion or cytoskeletal rearrangement. Taken together, our results showed the direct impact of miR-218 on the qualitative ECM content, leading to changes in the rigidity of the ECM as well as GBM cells. These features impacted by miR-218 overexpression collectively reduce the motility of cancer cells and increase their adhesiveness, thus conferring a phenotype closely related to that of normal cells. Collectively, our results indicate that miR-218 is a potent tumour suppressor in glioma with a large impact on the ECM and biomechanical properties of the cells. Additionally, we believe that cell mechanical properties can constitute a broad drug target space, allowing possible corrective modulation of tumour cell behaviour. These observations thus allow us to conclude that modulating the described interactions with direct impact on cell motility properties could be considered a promising therapeutic approach in glioblastoma.

\section{Abbreviations}


miRNA - micro RNA, ncRNA - non-coding RNA, , GBM - glioblastoma, SDC-2 - syndecan 2, TN-C tenascin C, ECM - extracellular matrix, AFM - atomic force microscopy, SCFS - single cell force spectroscopy, GAPDH - glyceraldehyde 3-phosphate dehydrogenase, HPRT - hypoxanthine phosphoribosyltransferase

\section{Declarations}

\section{Ethics approval and consent to participate}

Tissue samples used in this study were collected based on the the approval from the Karol Marcinkowski University of Medical Sciences in Poznan Ethical Committee (Consent nr. 46/13)

\section{Consent for publication}

Not applicable.

\section{Availability of data and materials}

All data generated or analysed during this study are included in this published article [and its supplementary information files].

\section{Competing interests}

The authors declare that they have no competing interests.

\section{Funding}

KK was supported by The National Centre for Research and Development programme (POWR.03.02.0000-1032/16).

\section{Authors' contributions}

MP, ML and KR designed experiments. MG, KK, MP, AR, PG, DW and JZ performed experiments. MG, KK, $\mathrm{MP}$ and $\mathrm{KR}$ wrote the manuscript. MG, KK, ML, and KR contributed to data analysis and discussed the results. All authors read and approved the final manuscript.

\section{Acknowledgements}

We thank the Laboratory of Subcellular Structures Analysis of the Institute of Bioorganic Chemistry, Polish Academy of Sciences in Poznan, for the facilitating the cell culture maintaining and the microscopic analysis.

\section{References}


1. Sasmita, A.O.; Wong, Y.P.; Ling, A.P.K. Biomarkers and therapeutic advances in glioblastoma multiforme. Asia Pac J Clin Oncol 2018, 14, 40-51, doi:10.1111/ajco.12756.

2. Vigneswaran, K.; Neill, S.; Hadjipanayis, C.G. Beyond the World Health Organization grading of infiltrating gliomas: advances in the molecular genetics of glioma classification. Ann Trans/ Med 2015, 3, 95, doi:10.3978/j.issn.2305-5839.2015.03.57.

3. Kim, J.; Lee, I.H.; Cho, H.J.; Park, C.K.; Jung, Y.S.; Kim, Y.; Nam, S.H.; Kim, B.S.; Johnson, M.D.; Kong, D.S., et al. Spatiotemporal Evolution of the Primary Glioblastoma Genome. Cancer Cel/ 2015, 28, 318328, doi:10.1016/j.ccell.2015.07.013.

4. Wei, S.C.; Yang, J. Forcing through Tumor Metastasis: The Interplay between Tissue Rigidity and Epithelial-Mesenchymal Transition. Trends Cell Biol 2016, 26, 111-120, doi:10.1016/j.tcb.2015.09.009.

5. Naba, A.; Clauser, K.R.; Hoersch, S.; Liu, H.; Carr, S.A.; Hynes, R.O. The matrisome: in silico definition and in vivo characterization by proteomics of normal and tumor extracellular matrices. Mol Cell Proteomics 2012, 11, M111 014647, doi:10.1074/mcp.M111.014647.

6. Gkretsi, V.; Stylianopoulos, T. Cell Adhesion and Matrix Stiffness: Coordinating Cancer Cell Invasion and Metastasis. Front Oncol 2018, 8, 145, doi:10.3389/fonc.2018.00145.

7. Acerbi, I.; Cassereau, L.; Dean, I.; Shi, Q.; Au, A.; Park, C.; Chen, Y.Y.; Liphardt, J.; Hwang, E.S.; Weaver, V.M. Human breast cancer invasion and aggression correlates with ECM stiffening and immune cell infiltration. Integr Biol (Camb) 2015, 7, 1120-1134, doi:10.1039/c5ib00040h.

8. Naba, A.; Clauser, K.R.; Lamar, J.M.; Carr, S.A.; Hynes, R.O. Extracellular matrix signatures of human mammary carcinoma identify novel metastasis promoters. Elife 2014, 3, e01308, doi:10.7554/eLife.01308.

9. Gjorevski, N.; Sachs, N.; Manfrin, A.; Giger, S.; Bragina, M.E.; Ordonez-Moran, P.; Clevers, H.; Lutolf, M.P. Designer matrices for intestinal stem cell and organoid culture. Nature 2016, 539, 560-564, doi:10.1038/nature20168.

10. Rianna, C.; Kumar, P.; Radmacher, M. The role of the microenvironment in the biophysics of cancer. Semin Cell Dev Bio/ 2018, 73, 107-114, doi:10.1016/j.semcdb.2017.07.022.

11. Goetz, J.G.; Minguet, S.; Navarro-Lerida, I.; Lazcano, J.J.; Samaniego, R.; Calvo, E.; Tello, M.; OstesoIbanez, T.; Pellinen, T.; Echarri, A., et al. Biomechanical remodeling of the microenvironment by stromal caveolin-1 favors tumor invasion and metastasis. Cell 2011, 146, 148-163, doi:10.1016/j.cell.2011.05.040.

12. Levental, K.R.; Yu, H.; Kass, L.; Lakins, J.N.; Egeblad, M.; Erler, J.T.; Fong, S.F.; Csiszar, K.; Giaccia, A.; Weninger, W., et al. Matrix crosslinking forces tumor progression by enhancing integrin signaling. Cell 2009, 139, 891-906, doi:10.1016/j.cell.2009.10.027.

13. Mansouri, R.; Hay, E.; Marie, P.J.; Modrowski, D. Role of syndecan-2 in osteoblast biology and pathology. Bonekey Rep 2015, 4, 666, doi:10.1038/bonekey.2015.33.

14. Mytilinaiou, M.; Nikitovic, D.; Berdiaki, A.; Kostouras, A.; Papoutsidakis, A.; Tsatsakis, A.M.; Tzanakakis, G.N. Emerging roles of syndecan 2 in epithelial and mesenchymal cancer progression. 
IUBMB Life 2017, 69, 824-833, doi:10.1002/iub.1678.

15. Vicente, C.M.; Ricci, R.; Nader, H.B.; Toma, L. Syndecan-2 is upregulated in colorectal cancer cells through interactions with extracellular matrix produced by stromal fibroblasts. BMC Cell Bio/ 2013, 14, 25, doi:10.1186/1471-2121-14-25.

16. Park, H.; Han, I.; Kwon, H.J.; Oh, E.S. Focal adhesion kinase regulates syndecan-2-mediated tumorigenic activity of HT1080 fibrosarcoma cells. Cancer Res 2005, 65, 9899-9905, doi:10.1158/0008-5472.CAN-05-1386.

17. Lee, J.H.; Park, H.; Chung, H.; Choi, S.; Kim, Y.; Yoo, H.; Kim, T.Y.; Hann, H.J.; Seong, I.; Kim, J., et al. Syndecan-2 regulates the migratory potential of melanoma cells. J Biol Chem 2009, 284, 27167 27175, doi:10.1074/jbc.M109.034678.

18. Choi, S.; Choi, Y.; Jun, E.; Kim, I.S.; Kim, S.E.; Jung, S.A.; Oh, E.S. Shed syndecan-2 enhances tumorigenic activities of colon cancer cells. Oncotarget 2015, 6, 3874-3886, doi:10.18632/oncotarget.2885.

19. De Oliveira, T.; Abiatari, I.; Raulefs, S.; Sauliunaite, D.; Erkan, M.; Kong, B.; Friess, H.; Michalski, C.W.; Kleeff, J. Syndecan-2 promotes perineural invasion and cooperates with K-ras to induce an invasive pancreatic cancer cell phenotype. Mol Cancer 2012, 11, 19, doi:10.1186/1476-4598-11-19.

20. Hua, R.; Yu, J.; Yan, X.; Ni, Q.; Zhi, X.; Li, X.; Jiang, B.; Zhu, J. Syndecan-2 in colorectal cancer plays oncogenic role via epithelial-mesenchymal transition and MAPK pathway. Biomed Pharmacother 2020, 121, 109630, doi:10.1016/j.biopha.2019.109630.

21. Brosicke, N.; van Landeghem, F.K.; Scheffler, B.; Faissner, A. Tenascin-C is expressed by human glioma in vivo and shows a strong association with tumor blood vessels. Cell Tissue Res 2013, 354, 409-430, doi:10.1007/s00441-013-1704-9.

22. Naik, A.; Al-Yahyaee, A.; Abdullah, N.; Sam, J.E.; Al-Zeheimi, N.; Yaish, M.W.; Adham, S.A. Neuropilin-1 promotes the oncogenic Tenascin-C/integrin beta3 pathway and modulates chemoresistance in breast cancer cells. BMC Cancer 2018, 18, 533, doi:10.1186/s12885-018-4446-y.

23. Gocheva, V.; Naba, A.; Bhutkar, A.; Guardia, T.; Miller, K.M.; Li, C.M.; Dayton, T.L.; Sanchez-Rivera, F.J.; Kim-Kiselak, C.; Jailkhani, N., et al. Quantitative proteomics identify Tenascin-C as a promoter of lung cancer progression and contributor to a signature prognostic of patient survival. Proc Natl Acad Sci U S A 2017, 114, E5625-E5634, doi:10.1073/pnas.1707054114.

24. Yang, Z.; Zhang, C.; Qi, W.; Cui, C.; Cui, Y.; Xuan, Y. Tenascin-C as a prognostic determinant of colorectal cancer through induction of epithelial-to-mesenchymal transition and proliferation. Exp Mol Pathol 2018, 105, 216-222, doi:10.1016/j.yexmp.2018.08.009.

25. Ambros, V. The functions of animal microRNAs. Nature 2004, 431, 350-355, doi:10.1038/nature02871.

26. Calin, G.A.; Croce, C.M. MicroRNA signatures in human cancers. Nat Rev Cancer 2006, 6, 857-866, doi:10.1038/nrc1997.

27. van Rooij, E.; Sutherland, L.B.; Liu, N.; Williams, A.H.; McAnally, J.; Gerard, R.D.; Richardson, J.A.; Olson, E.N. A signature pattern of stress-responsive microRNAs that can evoke cardiac hypertrophy 
and heart failure. Proc Natl Acad Sci U S A 2006, 103, 18255-18260, doi:10.1073/pnas.0608791103.

28. O'Connell, R.M.; Rao, D.S.; Chaudhuri, A.A.; Baltimore, D. Physiological and pathological roles for microRNAs in the immune system. Nat Rev Immuno/ 2010, 10, 111-122, doi:10.1038/nri2708.

29. Ciafre, S.A.; Galardi, S.; Mangiola, A.; Ferracin, M.; Liu, C.G.; Sabatino, G.; Negrini, M.; Maira, G.; Croce, C.M.; Farace, M.G. Extensive modulation of a set of microRNAs in primary glioblastoma. Biochem Biophys Res Commun 2005, 334, 1351-1358, doi:10.1016/j.bbrc.2005.07.030.

30. Li, Z.; Qian, R.; Zhang, J.; Shi, X. MiR-218-5p targets LHFPL3 to regulate proliferation, migration, and epithelial-mesenchymal transitions of human glioma cells. Biosci Rep 2019, 39, doi:10.1042/BSR20180879.

31. Zhang, Y.; Han, D.; Wei, W.; Cao, W.; Zhang, R.; Dong, Q.; Zhang, J.; Wang, Y.; Liu, N. MiR-218 Inhibited Growth and Metabolism of Human Glioblastoma Cells by Directly Targeting E2F2. Cell Mol Neurobiol 2015, 35, 1165-1173, doi:10.1007/s10571-015-0210-x.

32. Wu, Z.; Han, Y.; Li, Y.; Li, X.; Sun, T.; Chen, G.; Huang, Y.; Zhou, Y.; Du, Z. MiR-218-5p inhibits the stem cell properties and invasive ability of the A2B5(+)CD133(-) subgroup of human glioma stem cells. Oncol Rep 2016, 35, 869-877, doi:10.3892/or.2015.4418.

33. Piwecka, M.; Rolle, K.; Belter, A.; Barciszewska, A.M.; Zywicki, M.; Michalak, M.; Nowak, S.; NaskretBarciszewska, M.Z.; Barciszewski, J. Comprehensive analysis of microRNA expression profile in malignant glioma tissues. Mol Oncol 2015, 9, 1324-1340, doi:10.1016/j.molonc.2015.03.007.

34. Morris, E.J.; Geller, H.M. Induction of neuronal apoptosis by camptothecin, an inhibitor of DNA topoisomerase-l: evidence for cell cycle-independent toxicity. J Cell Biol 1996, 134, 757-770, doi:10.1083/jcb.134.3.757.

35. Wang, N.; Tytell, J.D.; Ingber, D.E. Mechanotransduction at a distance: mechanically coupling the extracellular matrix with the nucleus. Nat Rev Mol Cell Biol 2009, 10, 75-82, doi:10.1038/nrm2594.

36. Rotsch, C.; Radmacher, M. Drug-induced changes of cytoskeletal structure and mechanics in fibroblasts: an atomic force microscopy study. Biophys J 2000, 78, 520-535, doi:10.1016/S00063495(00)76614-8.

37. Ohgaki, H.; Kleihues, P. Genetic pathways to primary and secondary glioblastoma. Am J Pathol 2007, 170, 1445-1453, doi:10.2353/ajpath.2007.070011.

38. Xu, T.J.; Qiu, P.; Zhang, Y.B.; Yu, S.Y.; Xu, G.M.; Yang, W. MiR-148a inhibits the proliferation and migration of glioblastoma by targeting ITGA9. Hum Cell 2019, 32, 548-556, doi:10.1007/s13577-01900279-9.

39. Feng, L.; Ma, J.; Ji, H.; Liu, Y.; Hu, W. miR-330-5p suppresses glioblastoma cell proliferation and invasiveness through targeting ITGA5. Biosci Rep 2017, 37, doi:10.1042/BSR20170019.

40. Lei, D.; Zhang, F.; Yao, D.; Xiong, N.; Jiang, X.; Zhao, H. MiR-338-5p suppresses proliferation, migration, invasion, and promote apoptosis of glioblastoma cells by directly targeting EFEMP1. Biomed Pharmacother 2017, 89, 957-965, doi:10.1016/j.biopha.2017.01.137.

41. Li, Y.; Wang, Y.; Yu, L.; Sun, C.; Cheng, D.; Yu, S.; Wang, Q.; Yan, Y.; Kang, C.; Jin, S., et al. miR-146b-5p inhibits glioma migration and invasion by targeting MMP16. Cancer Lett 2013, 339, 260-269, 
doi:10.1016/j.canlet.2013.06.018.

42. Dickinson, R.E.; Dallol, A.; Bieche, I.; Krex, D.; Morton, D.; Maher, E.R.; Latif, F. Epigenetic inactivation of SLIT3 and SLIT1 genes in human cancers. Br J Cancer 2004, 91, 2071-2078, doi:10.1038/sj.bjc.6602222.

43. Shi, J.; Yang, L.; Wang, T.; Zhang, J.; Guo, X.; Huo, X.; Niu, H. miR-218 is downregulated and directly targets SH3GL1 in childhood medulloblastoma. Mol Med Rep 2013, 8, 1111-1117, doi:10.3892/mmr.2013.1639.

44. Guan, H.; Wei, G.; Wu, J.; Fang, D.; Liao, Z.; Xiao, H.; Li, M.; Li, Y. Down-regulation of miR-218-2 and its host gene SLIT3 cooperate to promote invasion and progression of thyroid cancer. J Clin Endocrinol Metab 2013, 98, E1334-1344, doi:10.1210/jc.2013-1053.

45. Zhu, L.; Tu, H.; Liang, Y.; Tang, D. MiR-218 produces anti-tumor effects on cervical cancer cells in vitro. World J Surg Onco/ 2018, 16, 204, doi:10.1186/s12957-018-1506-3.

46. Bourdon, M.A.; Wikstrand, C.J.; Furthmayr, H.; Matthews, T.J.; Bigner, D.D. Human gliomamesenchymal extracellular matrix antigen defined by monoclonal antibody. Cancer Res 1983, 43, 2796-2805.

47. Herold-Mende, C.; Mueller, M.M.; Bonsanto, M.M.; Schmitt, H.P.; Kunze, S.; Steiner, H.H. Clinical impact and functional aspects of tenascin-C expression during glioma progression. Int J Cancer 2002, 98, 362-369, doi:10.1002/ijc.10233.

48. Mustafa, D.A.; Dekker, L.J.; Stingl, C.; Kremer, A.; Stoop, M.; Sillevis Smitt, P.A.; Kros, J.M.; Luider, T.M. A proteome comparison between physiological angiogenesis and angiogenesis in glioblastoma. $\mathrm{Mol}$ Cell Proteomics 2012, 11, M111 008466, doi:10.1074/mcp.M111.008466.

49. Chiquet-Ehrismann, R.; Chiquet, M. Tenascins: regulation and putative functions during pathological stress. J Patho/ 2003, 200, 488-499, doi:10.1002/path.1415.

50. Rolle, K.; Nowak, S.; Wyszko, E.; Nowak, M.; Zukiel, R.; Piestrzeniewicz, R.; Gawronska, I.; Barciszewska, M.Z.; Barciszewski, J. Promising human brain tumors therapy with interference RNA intervention (iRNAi). Cancer Biol Ther 2010, 9, 396-406, doi:10.4161/cbt.9.5.10958.

51. Chung, H.; Lee, J.H.; Jeong, D.; Han, I.O.; Oh, E.S. Melanocortin 1 receptor regulates melanoma cell migration by controlling syndecan-2 expression. J Biol Chem 2012, 287, 19326-19335, doi:10.1074/jbc.M111.334730.

52. Munesue, S.; Kusano, Y.; Oguri, K.; Itano, N.; Yoshitomi, Y.; Nakanishi, H.; Yamashina, I.; Okayama, M. The role of syndecan-2 in regulation of actin-cytoskeletal organization of Lewis lung carcinomaderived metastatic clones. Biochem J 2002, 363, 201-209, doi:10.1042/0264-6021:3630201.

53. He, X.; Lee, B.; Jiang, Y. Cell-ECM Interactions in Tumor Invasion. Adv Exp Med Bio/ 2016, 936, 73-91, doi:10.1007/978-3-319-42023-3_4.

54. Lu, P.; Weaver, V.M.; Werb, Z. The extracellular matrix: a dynamic niche in cancer progression. J Cell Biol 2012, 196, 395-406, doi:10.1083/jcb.201102147.

55. Pickup, M.W.; Mouw, J.K.; Weaver, V.M. The extracellular matrix modulates the hallmarks of cancer. EMBO Rep 2014, 15, 1243-1253, doi:10.15252/embr.201439246. 
56. Lo, C.M.; Wang, H.B.; Dembo, M.; Wang, Y.L. Cell movement is guided by the rigidity of the substrate. Biophys J 2000, 79, 144-152, doi:10.1016/S0006-3495(00)76279-5.

57. Ulrich, T.A.; de Juan Pardo, E.M.; Kumar, S. The mechanical rigidity of the extracellular matrix regulates the structure, motility, and proliferation of glioma cells. Cancer Res 2009, 69, 4167-4174, doi:10.1158/0008-5472.CAN-08-4859.

58. Hatzikirou, H.; Basanta, D.; Simon, M.; Schaller, K.; Deutsch, A. 'Go or grow': the key to the emergence of invasion in tumour progression? Math Med Bio/ 2012, 29, 49-65, doi:10.1093/imammb/dqq011.

59. Godlewski, J.; Nowicki, M.O.; Bronisz, A.; Nuovo, G.; Palatini, J.; De Lay, M.; Van Brocklyn, J.; Ostrowski, M.C.; Chiocca, E.A.; Lawler, S.E. MicroRNA-451 regulates LKB1/AMPK signaling and allows adaptation to metabolic stress in glioma cells. Mol Cel/ 2010, 37, 620-632, doi:10.1016/j.molcel.2010.02.018.

60. Binnig, G.; Quate, C.F.; Gerber, C. Atomic force microscope. Phys Rev Lett 1986, 56, 930-933, doi:10.1103/PhysRevLett.56.930.

61. Zemla, J.; Danilkiewicz, J.; Orzechowska, B.; Pabijan, J.; Seweryn, S.; Lekka, M. Atomic force microscopy as a tool for assessing the cellular elasticity and adhesiveness to identify cancer cells and tissues. Semin Cell Dev Bio/ 2018, 73, 115-124, doi:10.1016/j.semcdb.2017.06.029.

62. Nakada, M.; Yamada, A.; Takino, T.; Miyamori, H.; Takahashi, T.; Yamashita, J.; Sato, H. Suppression of membrane-type 1 matrix metalloproteinase (MMP)-mediated MMP-2 activation and tumor invasion by testican 3 and its splicing variant gene product, N-Tes. Cancer Res 2001, 61, 8896-8902.

63. Li, I.T.; Ha, T.; Chemla, Y.R. Mapping cell surface adhesion by rotation tracking and adhesion footprinting. Sci Rep 2017, 7, 44502, doi:10.1038/srep44502.

64. Lomakina, E.B.; Marsh, G.; Waugh, R.E. Cell surface topography is a regulator of molecular interactions during chemokine-induced neutrophil spreading. Biophys $J \mathbf{2 0 1 4}, 107,1302-1312$, doi:10.1016/j.bpj.2014.07.062.

65. Paszek, M.J.; Zahir, N.; Johnson, K.R.; Lakins, J.N.; Rozenberg, G.I.; Gefen, A.; Reinhart-King, C.A.; Margulies, S.S.; Dembo, M.; Boettiger, D., et al. Tensional homeostasis and the malignant phenotype. Cancer Cel/ 2005, 8, 241-254, doi:10.1016/j.ccr.2005.08.010.

66. Mahesparan, R.; Read, T.A.; Lund-Johansen, M.; Skaftnesmo, K.O.; Bjerkvig, R.; Engebraaten, O. Expression of extracellular matrix components in a highly infiltrative in vivo glioma model. Acta Neuropatho/ 2003, 105, 49-57, doi:10.1007/s00401-002-0610-0.

67. Hayashi, K.; Iwata, M. Stiffness of cancer cells measured with an AFM indentation method. $J$ Mech Behav Biomed Mater 2015, 49, 105-111, doi:10.1016/j.jmbbm.2015.04.030.

68. Li, Q.S.; Lee, G.Y.; Ong, C.N.; Lim, C.T. AFM indentation study of breast cancer cells. Biochem Biophys Res Commun 2008, 374, 609-613, doi:10.1016/j.bbrc.2008.07.078.

69. Ramos, J.R.; Pabijan, J.; Garcia, R.; Lekka, M. The softening of human bladder cancer cells happens at an early stage of the malignancy process. Beilstein J Nanotechno/ 2014, 5, 447-457, doi:10.3762/bjnano.5.52. 
70. Lekka, M.; Gil, D.; Pogoda, K.; Dulinska-Litewka, J.; Jach, R.; Gostek, J.; Klymenko, O.; PrauznerBechcicki, S.; Stachura, Z.; Wiltowska-Zuber, J., et al. Cancer cell detection in tissue sections using AFM. Arch Biochem Biophys 2012, 518, 151-156, doi:10.1016/j.abb.2011.12.013.

71. Minelli, E.; Sassun, T.E.; Papi, M.; Palmieri, V.; Palermo, F.; Perini, G.; Antonelli, M.; Gianno, F.; Maulucci, G.; Ciasca, G., et al. Nanoscale mechanics of brain abscess: An atomic force microscopy study. Micron 2018, 113, 34-40, doi:10.1016/j.micron.2018.06.012.

72. Lee, S.M.; Nguyen, T.H.; Na, K.; Cho, I.J.; Woo, D.H.; Oh, J.E.; Lee, C.J.; Yoon, E.S. Nanomechanical measurement of astrocyte stiffness correlated with cytoskeletal maturation. $J$ Biomed Mater Res $A$ 2015, 103, 365-370, doi:10.1002/jbm.a.35174.

73. van Dommelen, J.A.; van der Sande, T.P.; Hrapko, M.; Peters, G.W. Mechanical properties of brain tissue by indentation: interregional variation. J Mech Behav Biomed Mater 2010, 3, 158-166, doi:10.1016/j.jmbbm.2009.09.001.

74. Budday, S.; Nay, R.; de Rooij, R.; Steinmann, P.; Wyrobek, T.; Ovaert, T.C.; Kuhl, E. Mechanical properties of gray and white matter brain tissue by indentation. J Mech Behav Biomed Mater 2015, 46, 318-330, doi:10.1016/j.jmbbm.2015.02.024.

75. Liu, Y.; Yan, W.; Zhang, W.; Chen, L.; You, G.; Bao, Z.; Wang, Y.; Wang, H.; Kang, C.; Jiang, T. MiR-218 reverses high invasiveness of glioblastoma cells by targeting the oncogenic transcription factor LEF1. Oncol Rep 2012, 28, 1013-1021, doi:10.3892/or.2012.1902.

76. Song, L.; Huang, Q.; Chen, K.; Liu, L.; Lin, C.; Dai, T.; Yu, C.; Wu, Z.; Li, J. miR-218 inhibits the invasive ability of glioma cells by direct downregulation of IKK-beta. Biochem Biophys Res Commun 2010, 402, 135-140, doi:10.1016/j.bbrc.2010.10.003.

77. Tu, Y.; Gao, X.; Li, G.; Fu, H.; Cui, D.; Liu, H.; Jin, W.; Zhang, Y. MicroRNA-218 inhibits glioma invasion, migration, proliferation, and cancer stem-like cell self-renewal by targeting the polycomb group gene Bmi1. Cancer Res 2013, 73, 6046-6055, doi:10.1158/0008-5472.CAN-13-0358.

78. Liang, H.; Wang, R.; Jin, Y.; Li, J.; Zhang, S. MiR-422a acts as a tumor suppressor in glioblastoma by targeting PIK3CA. Am J Cancer Res 2016, 6, 1695-1707.

79. Zhou, F.; Li, Y.; Hao, Z.; Liu, X.; Chen, L.; Cao, Y.; Liang, Z.; Yuan, F.; Liu, J.; Wang, J., et al. MicroRNA300 inhibited glioblastoma progression through ROCK1. Oncotarget 2016, 7, 36529-36538, doi:10.18632/oncotarget.9068.

80. Liu, J.; Liu, D.; Yang, Z.; Yang, Z. High LAMC1 expression in glioma is associated with poor prognosis. Onco Targets Ther 2019, 12, 4253-4260, doi:10.2147/OTT.S205333.

81. Gingras, M.C.; Roussel, E.; Bruner, J.M.; Branch, C.D.; Moser, R.P. Comparison of cell adhesion molecule expression between glioblastoma multiforme and autologous normal brain tissue. $J$ Neuroimmuno/ 1995, 57, 143-153, doi:10.1016/0165-5728(94)00178-q.

82. Kumar, S.; Lu, B.; Dixit, U.; Hossain, S.; Liu, Y.; Li, J.; Hornbeck, P.; Zheng, W.; Sowalsky, A.G.; Kotula, L., et al. Reciprocal regulation of Abl kinase by Crk Y251 and Abi1 controls invasive phenotypes in glioblastoma. Oncotarget 2015, 6, 37792-37807, doi:10.18632/oncotarget.6096. 
83. Liu, G.; Yan, T.; Li, X.; Sun, J.; Zhang, B.; Wang, H.; Zhu, Y. Daam1 activates RhoA to regulate Wnt5ainduced glioblastoma cell invasion. Oncol Rep 2018, 39, 465-472, doi:10.3892/or.2017.6124.

84. Li, Z.; Hu, C.; Zhen, Y.; Pang, B.; Yi, H.; Chen, X. Pristimerin inhibits glioma progression by targeting AGO2 and PTPN1 expression via miR-542-5p. Biosci Rep 2019, 39, doi:10.1042/BSR20182389.

85. Mathew, L.K.; Skuli, N.; Mucaj, V.; Lee, S.S.; Zinn, P.O.; Sathyan, P.; Imtiyaz, H.Z.; Zhang, Z.; Davuluri, R.V.; Rao, S., et al. miR-218 opposes a critical RTK-HIF pathway in mesenchymal glioblastoma. Proc Natl Acad Sci U S A 2014, 111, 291-296, doi:10.1073/pnas.1314341111.

86. Meseguer, S.; Panadero, J.; Navarro-Gonzalez, C.; Villarroya, M.; Boutoual, R.; Comi, G.P.; Armengod, M.E. The MELAS mutation m.3243A>G promotes reactivation of fetal cardiac genes and an epithelial-mesenchymal transition-like program via dysregulation of miRNAs. Biochim Biophys Acta Mol Basis Dis 2018, 1864, 3022-3037, doi:10.1016/j.bbadis.2018.06.014.

87. Yang, Y.; Ding, L.; Hu, Q.; Xia, J.; Sun, J.; Wang, X.; Xiong, H.; Gurbani, D.; Li, L.; Liu, Y., et al. MicroRNA218 functions as a tumor suppressor in lung cancer by targeting IL-6/STAT3 and negatively correlates with poor prognosis. Mol Cancer 2017, 16, 141, doi:10.1186/s12943-017-0710-z.

88. Okura, H.; Golbourn, B.J.; Shahzad, U.; Agnihotri, S.; Sabha, N.; Krieger, J.R.; Figueiredo, C.A.; Chalil, A.; Landon-Brace, N.; Riemenschneider, A., et al. A role for activated Cdc42 in glioblastoma multiforme invasion. Oncotarget 2016, 7, 56958-56975, doi:10.18632/oncotarget.10925.

89. Cheng, W.Y.; Chiao, M.T.; Liang, Y.J.; Yang, Y.C.; Shen, C.C.; Yang, C.Y. Luteolin inhibits migration of human glioblastoma U-87 MG and T98G cells through downregulation of Cdc42 expression and PI3K/AKT activity. Mol Biol Rep 2013, 40, 5315-5326, doi:10.1007/s11033-013-2632-1.

90. Han, D.; Yu, T.; Dong, N.; Wang, B.; Sun, F.; Jiang, D. Napabucasin, a novel STAT3 inhibitor suppresses proliferation, invasion and stemness of glioblastoma cells. J Exp Clin Cancer Res 2019, 38, 289, doi:10.1186/s13046-019-1289-6.

91. Chen, X.C.; Wei, X.T.; Guan, J.H.; Shu, H.; Chen, D. EGF stimulates glioblastoma metastasis by induction of matrix metalloproteinase-9 in an EGFR-dependent mechanism. Oncotarget 2017, 8, 65969-65982, doi:10.18632/oncotarget.19622.

92. Zhang, S.; Qi, Q. MTSS1 suppresses cell migration and invasion by targeting CTTN in glioblastoma. J Neuroonco/ 2015, 121, 425-431, doi:10.1007/s11060-014-1656-2.

93. Wang, L.; Zhao, K.; Ren, B.; Zhu, M.; Zhang, C.; Zhao, P.; Zhou, H.; Chen, L.; Yu, S.; Yang, X. Expression of cortactin in human gliomas and its effect on migration and invasion of glioma cells. Oncol Rep 2015, 34, 1815-1824, doi:10.3892/or.2015.4156.

94. Sen, S.; Dong, M.; Kumar, S. Isoform-specific contributions of alpha-actinin to glioma cell mechanobiology. PLoS One 2009, 4, e8427, doi:10.1371/journal.pone.0008427.

95. Yu, G.; Wang, Z.; Zeng, S.; Liu, S.; Zhu, C.; Xu, R.; Liu, R.E. Paeoniflorin Inhibits Hepatocyte Growth Factor- (HGF-) Induced Migration and Invasion and Actin Rearrangement via Suppression of c-MetMediated RhoA/ROCK Signaling in Glioblastoma. Biomed Res Int 2019, 2019, 9053295, doi:10.1155/2019/9053295. 
96. Stylli, S.S.; I, S.T.; Kaye, A.H.; Lock, P. Prognostic significance of Tks5 expression in gliomas. J Clin Neurosci 2012, 19, 436-442, doi:10.1016/j.jocn.2011.11.013.

97. Chen, Y.C.; Baik, M.; Byers, J.T.; Chen, K.T.; French, S.W.; Diaz, B. TKS5-positive invadopodia-like structures in human tumor surgical specimens. Exp Mol Patho/ 2019, 106, 17-26, doi:10.1016/j.yexmp.2018.11.005.

\section{Figures}

a

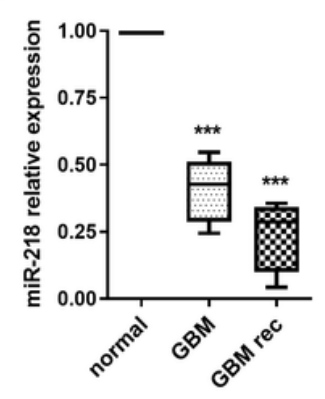

b

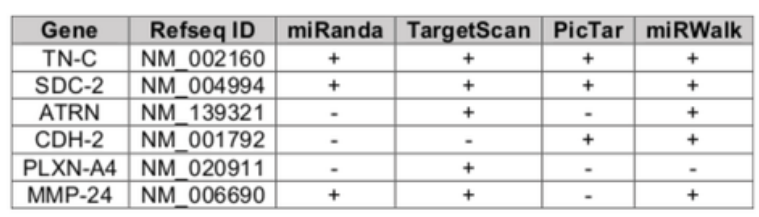

C

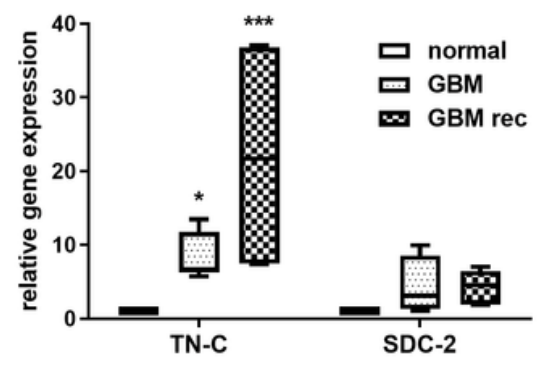

\section{Figure 1}

miR-218 expression in primary (GBM) and recurrent glioblastoma (GBM rec) tissues and its putative target mRNAs. (a) qRT-PCR analysis of GBM $(n=10)$ and GBM rec samples $(n=9)$ in comparison to a healthy brain tissue sample $(n=1)$. Data are shown as the mean \pm SD values. One-way ANOVA, post hoc Bonferroni test, $\star \star \star ~ p<0.001$. (b) miR-218 target prediction with miRanda, TargetScan, PicTar and miRWalk software. (c) qRT-PCR analysis of the tenascin-C and syndecan-2 mRNA expression levels in GBM and GBM rec tissues in comparison to RNA from healthy brain tissue. Data are shown as the mean $\pm S D$ values. Mixed-model analysis, post hoc Bonferroni test; * $p<0.05, * \star \star p<0.001$. 
a
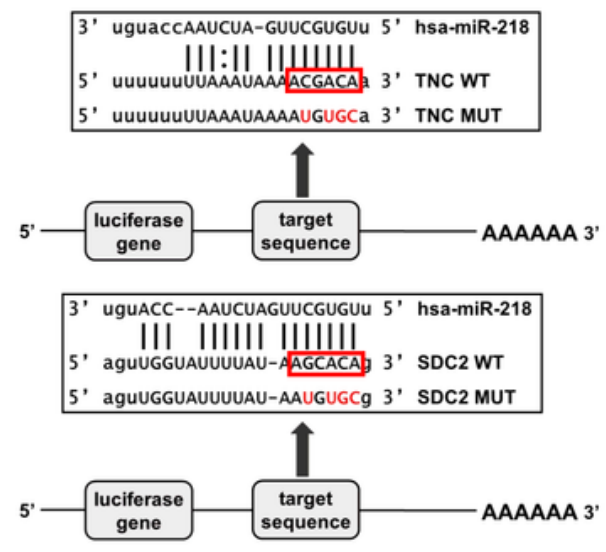

C

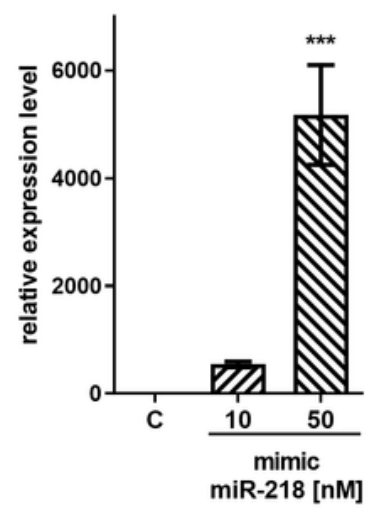

e

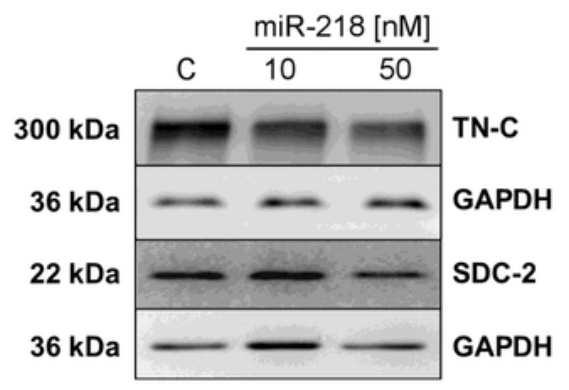

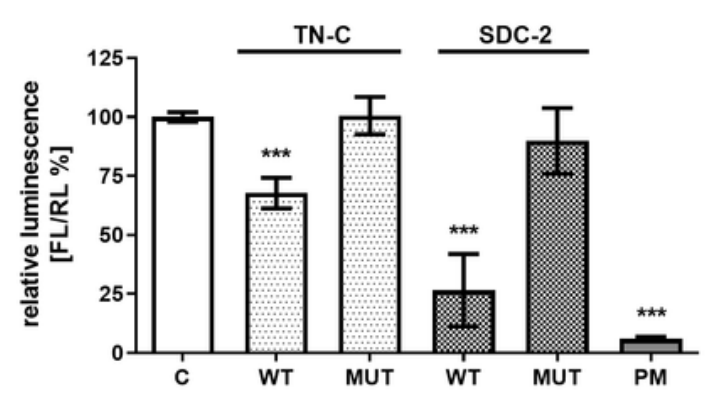

d

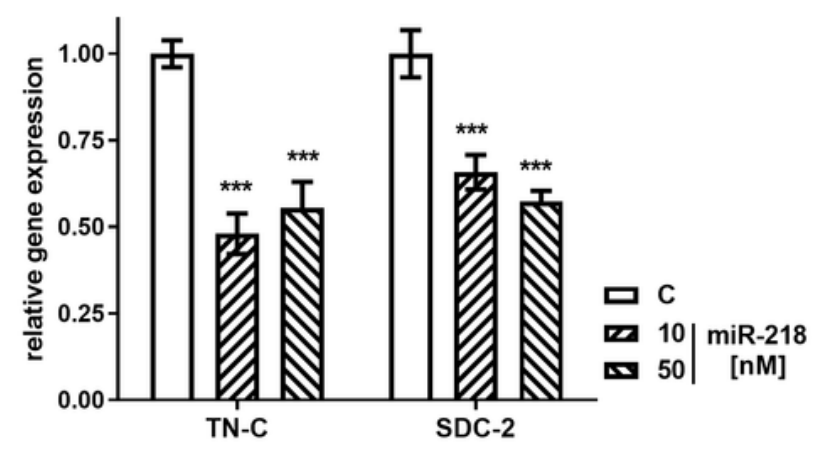

f

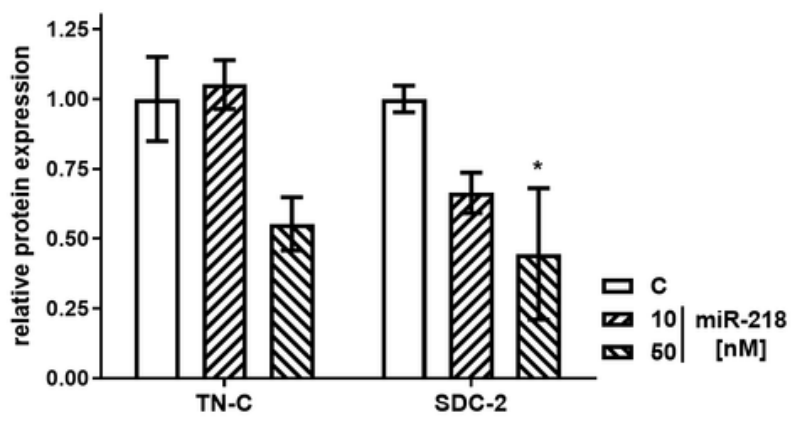

Figure 2

Regulation of TN-C and SDC-2 by miR-218. (a) Schematic representation of the interactions of miR-218 with the 3'UTRs of its targets. The seed region is enclosed in a red box. The putative conserved sequences in the SDC-2 and TN-C targets are denoted the wild type (WT). The non-conserved nucleotides within the seed region of the mutant $3^{\prime} U T R s$ are marked in red in the construct named "mutant" (MUT). (b) Relative repression of luciferase expression. Reporter constructs carrying a single binding site were 
tested. miR-218 activity in 5 constructs was measured in parallel (Control-C, WT, MUT and perfect match -PT as a positive control in the experiment). Data are shown as the mean \pm SD values. ${ }^{\star} \star * \quad p<0.001$. (c) Overexpression of miR-218 as a result of miR-218 mimic transfection, as evaluated by qRT-PCR. (d) The quantified effects of transfection of $\mathrm{U}-118 \mathrm{MG}$ cells with the miR-218 mimic at $10 \mathrm{nM}$ and $50 \mathrm{nM}$ concentrations on mRNA levels, as measured by qRT-PCR, and on protein levels, as established by Western blot analysis $(e, f)$. Cells transfected with scrambled siRNA were used as the control (C). Data are shown as the mean \pm SD values. Two-way ANOVA, post hoc Bonferroni test; * $p<0.05, * \star * ~ p<0.001$.

a

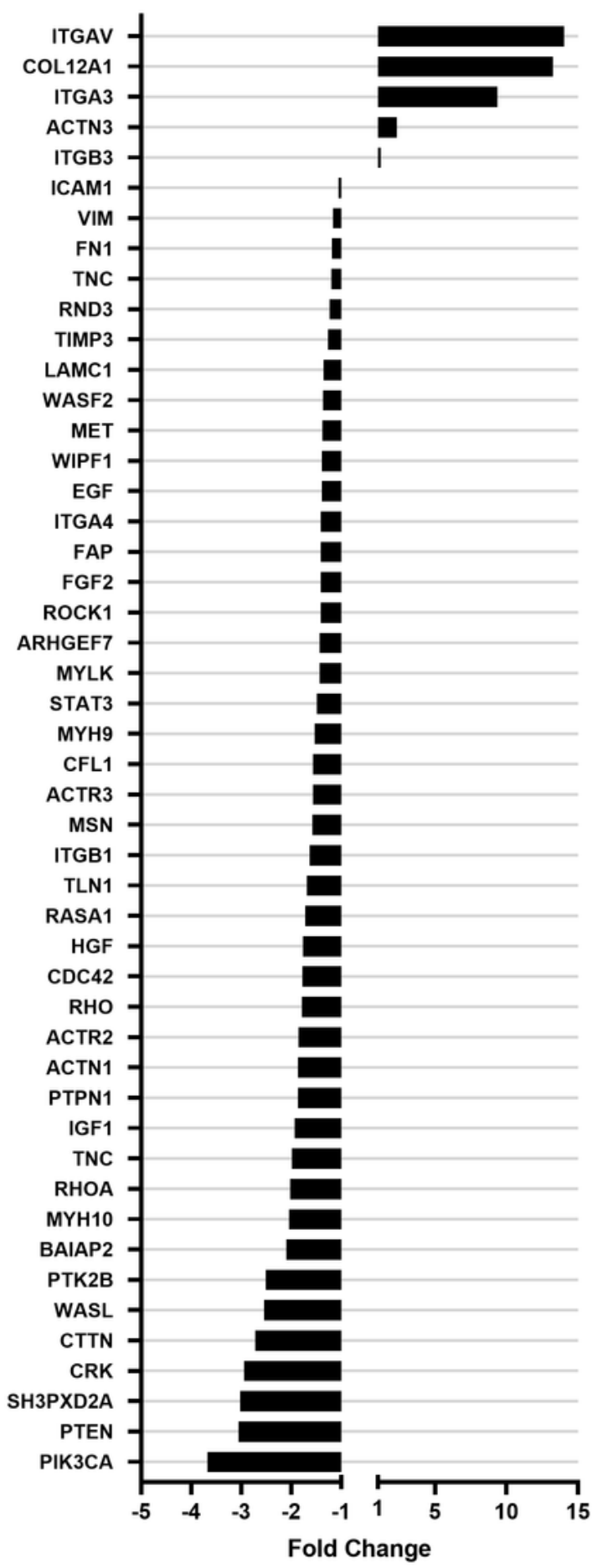

b

\begin{tabular}{|c|c|c|c|}
\hline gene & fold change & p-value & RefSeq record \\
\hline ITGAV & 14,0419 & 0,049032 & NM_002210 \\
\hline COL12A1 & 13,2538 & 0,043311 & NM_004370 \\
\hline ITGA3 & 9,3718 & 0,03991 & NM_002204 \\
\hline ACTN3 & 2,3268 & 0,037733 & NM_001104 \\
\hline ITGB3 & 1,1824 & 0,045621 & NM_000212 \\
\hline ICAM1 & $-1,0527$ & 0,049994 & NM_000201 \\
\hline VIM & $-1,16366$ & 0,04722 & NM_003380 \\
\hline FN1 & $-1,1849$ & 0,046053 & NM_002026 \\
\hline RND3 & $-1,2241$ & 0,044132 & NM_005168 \\
\hline TIMP3 & $-1,26043$ & 0,042594 & NM_000362 \\
\hline LAMC1 & $-1,34694$ & 0,048150 & NM_002293 \\
\hline WASF2 & $-1,3645$ & 0,045001 & NM_006990 \\
\hline MET & $-1,3771$ & 0,013717 & NM_000245 \\
\hline WIPF1 & $-1,3835$ & 0,020224 & NM_003387 \\
\hline EGF & $-1,3867$ & 0,025987 & NM_001963 \\
\hline FAP & $-1,4093$ & 0,016415 & NM_004460 \\
\hline ITGA4 & $-1,4093$ & 0,025599 & NM_000885 \\
\hline ROCK1 & $-1,4126$ & 0,006 & NM_005406 \\
\hline FGF2 & $-1,4126$ & 0,014704 & NM_002006 \\
\hline ARHGEF7 & $-1,4224$ & 0,00922 & NM_003899 \\
\hline MYLK & $-1,4257$ & 0,017474 & NM_053025 \\
\hline STAT3 & $-1,4828$ & 0,042723 & NM_003150 \\
\hline MYH9 & $-1,5245$ & 0,021593 & NM_002473 \\
\hline CFL1 & $-1,5637$ & 0,035133 & NM_005507 \\
\hline ACTR3 & $-1,5674$ & 0,027278 & NM_005721 \\
\hline MSN & $-1,571$ & 0,001185 & NM_002444 \\
\hline ITGB1 & $-1,6339$ & 0,040562 & NM_002211 \\
\hline TLN1 & $-1,6876$ & 0,000969 & NM_006289 \\
\hline RASA1 & $-1,7231$ & 0,011208 & NM_002890 \\
\hline HGF & $-1,7634$ & 0,031988 & NM_000601 \\
\hline $\mathrm{CDC} 42$ & $-1,7715$ & 0,032539 & NM_001791 \\
\hline $\mathrm{RHO}$ & $-1,7839$ & 0,044098 & NM_000539 \\
\hline ACTR2 & $-1,8553$ & 0,004925 & NM_005722 \\
\hline PTPN1 & $-1,8682$ & 0,000465 & NM_002827 \\
\hline ACTN1 & $-1,8682$ & 0,01462 & NM_001102 \\
\hline IGF1 & $-1,9341$ & 0,020683 & NM_000618 \\
\hline TNC & $-1,9852$ & 0,031457 & NM_002160 \\
\hline RHOA & $-2,0162$ & 0,048735 & NM_001664 \\
\hline MYH10 & $-2,035$ & 0,021525 & NM_005964 \\
\hline BAIAP2 & $-2,1019$ & 0,000482 & NM_006340 \\
\hline PTK2B & $-2,5111$ & 0,018089 & NM_004103 \\
\hline WASL & $-2,5344$ & 0,00436 & NM_003941 \\
\hline CTTN & $-2,7226$ & 0,000898 & NM_005231 \\
\hline CRK & $-2,9383$ & 0,00659 & NM_016823 \\
\hline SH3PXD2A & $-3,0209$ & 0,000972 & NM_014631 \\
\hline PTEN & $-3,056$ & 0,044654 & NM_000314 \\
\hline PIK3CA & $-3,6765$ & 0,042649 & NM_006218 \\
\hline
\end{tabular}


Figure 3

Cluster analysis of mRNAs encoding ECM components that were differentially regulated in the GBM cell line after miR-218 transfection. (a) The quantified effects of transfection of U-118 MG cells with the miR218 mimic at a $50 \mathrm{nM}$ concentration on the expression levels of genes, as determined by qRT-PCR of a Human Cell Motility and Extracellular Matrix \& Adhesion Molecules RT2 Profiler PCR Array. Cells transfected with scrambled siRNA were used as the control. (b) Table containing numerical results along with the corresponding $p$-values. Only statistically significant results are presented $(p<0.05)$.

a

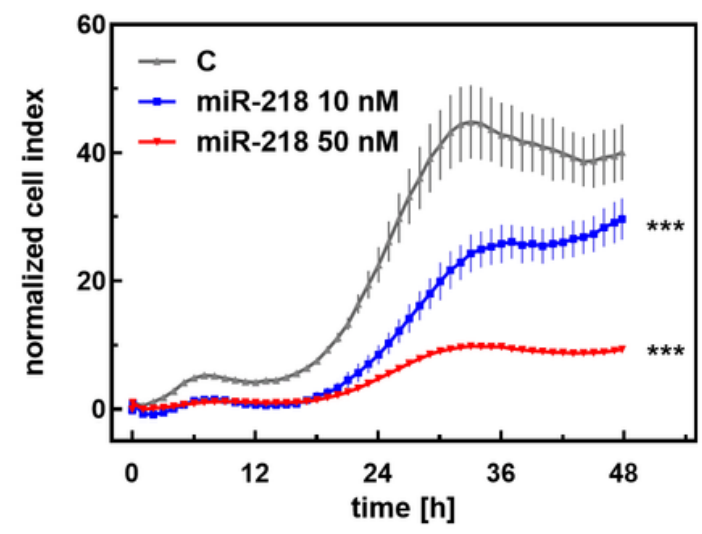

C

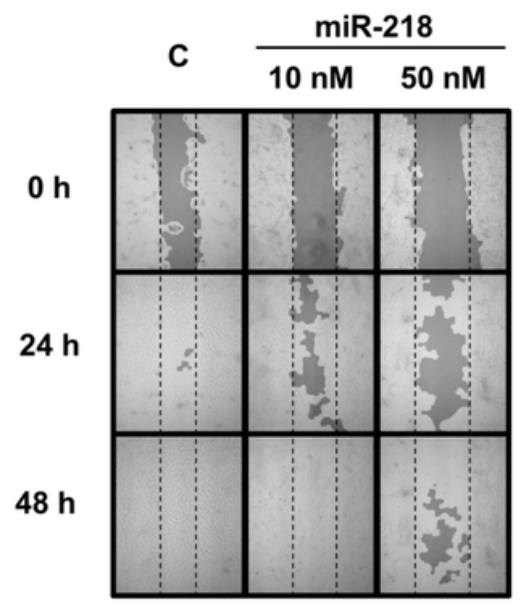

e

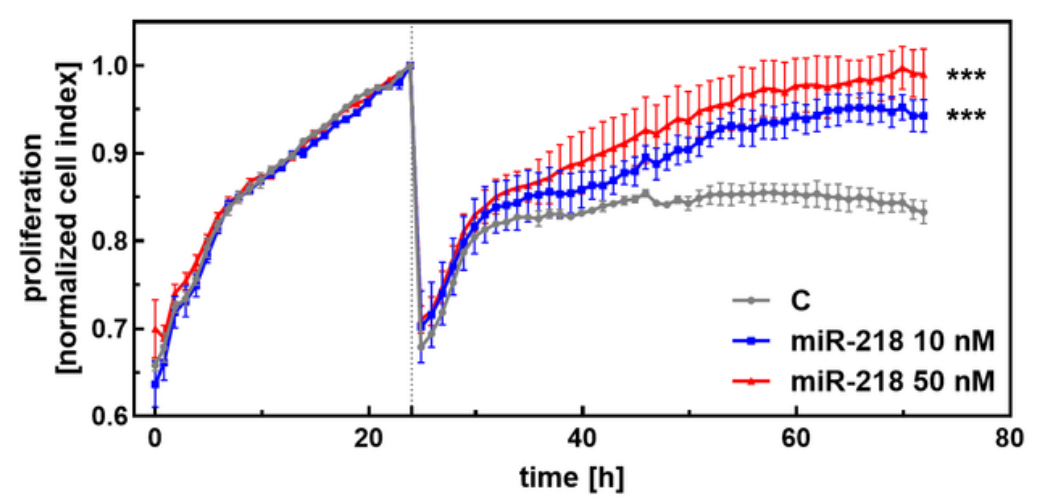

b

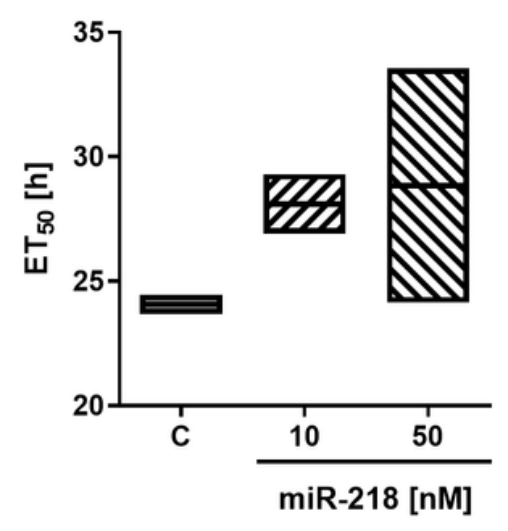

d

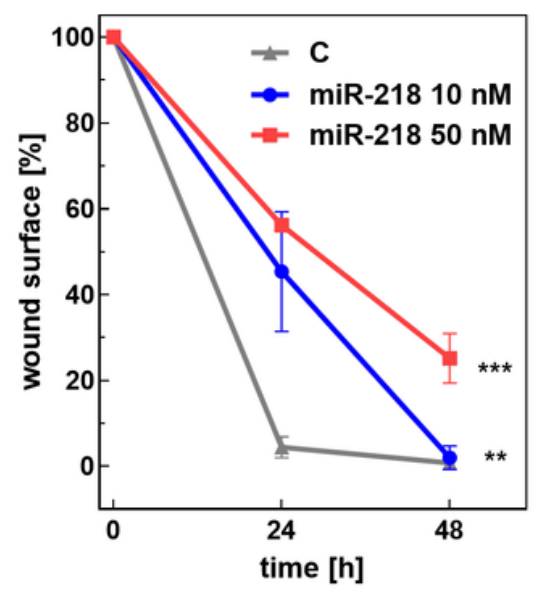

f

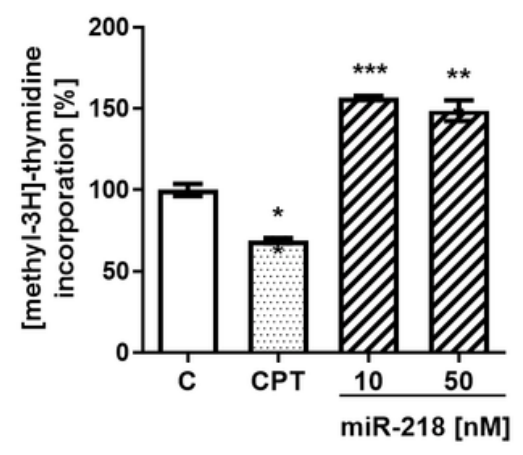

Figure 4 
Effect of miR-218 on the migration and proliferation of glioblastoma cells. (a) The migration of U-118 MG cancer cells was studied using an XCELLigence system. Cells in serum-depleted medium were transfected with the miR-218 mimic (10 and $50 \mathrm{nM})$. Data are shown as the mean \pm SD values. One-way ANOVA, post hoc Bonferroni test, $* \star \star p<0.001$. (b) The half-maximal effective time (ET50) was calculated for each miR-218 concentration to generate dose-response curves. The ET50 values were normalized to those of untreated cells and are plotted as the normalized ET50 of cell migration against the miR-218 concentration. (c) The wound healing assay after miR-218 mimic transfection. The dark grey areas indicate the surface area of the wound. (d) The calculation of the wound area (\%) 24 and 48 hrs post transfection. Control cells (C) were treated with scrambled siRNA. Data are shown as the mean \pm SD values. One-way ANOVA, post hoc Bonferroni test; ${ }^{* \star} p<0.01$, ${ }^{\star \star \star} p<0.001$. (e) Proliferation of U-118 MG cancer cells analysed with the xCELLigence system. Cells were transfected with the miR-218 mimic (10 and $50 \mathrm{nM}$ ). Data are shown as the mean \pm SD values. One-way ANOVA, post hoc Bonferroni test; ${ }^{*} \mathrm{p}<$ $0.05,{ }^{* *} p<0.01$. (f) The thymidine incorporation assay on miR-218 mimic-transfected cells. As the positive control, cells treated with camptothecin were used. One-way ANOVA, post hoc Bonferroni test; * $p$ $<0.05, * \star p<0.01, * \star * p<0.001$. 
a

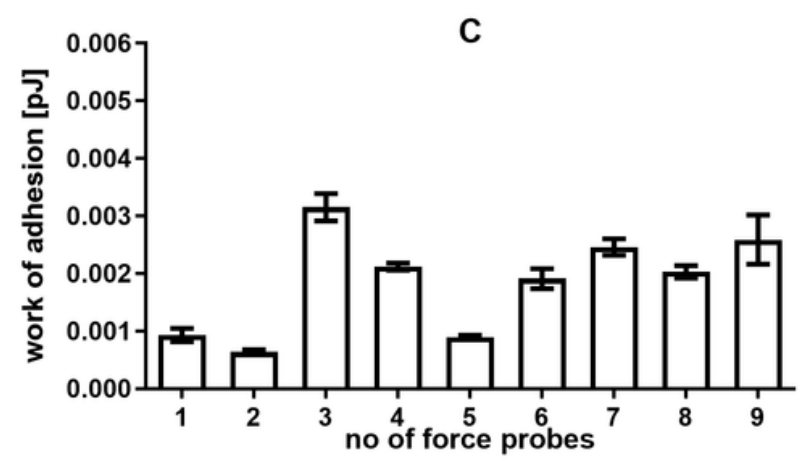

C

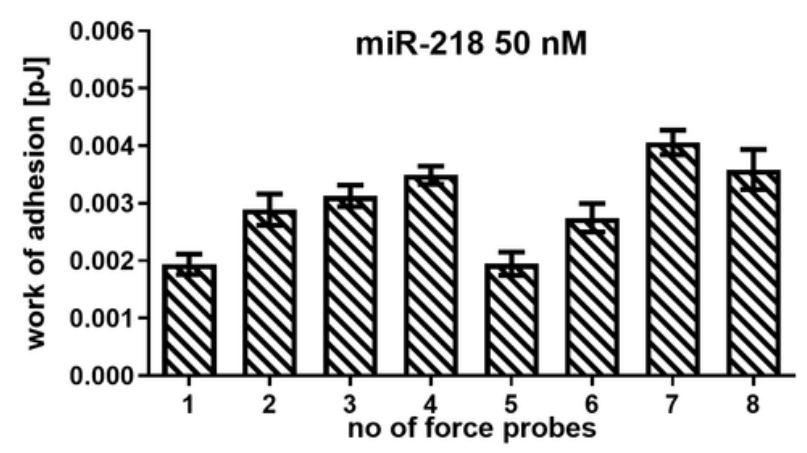

b
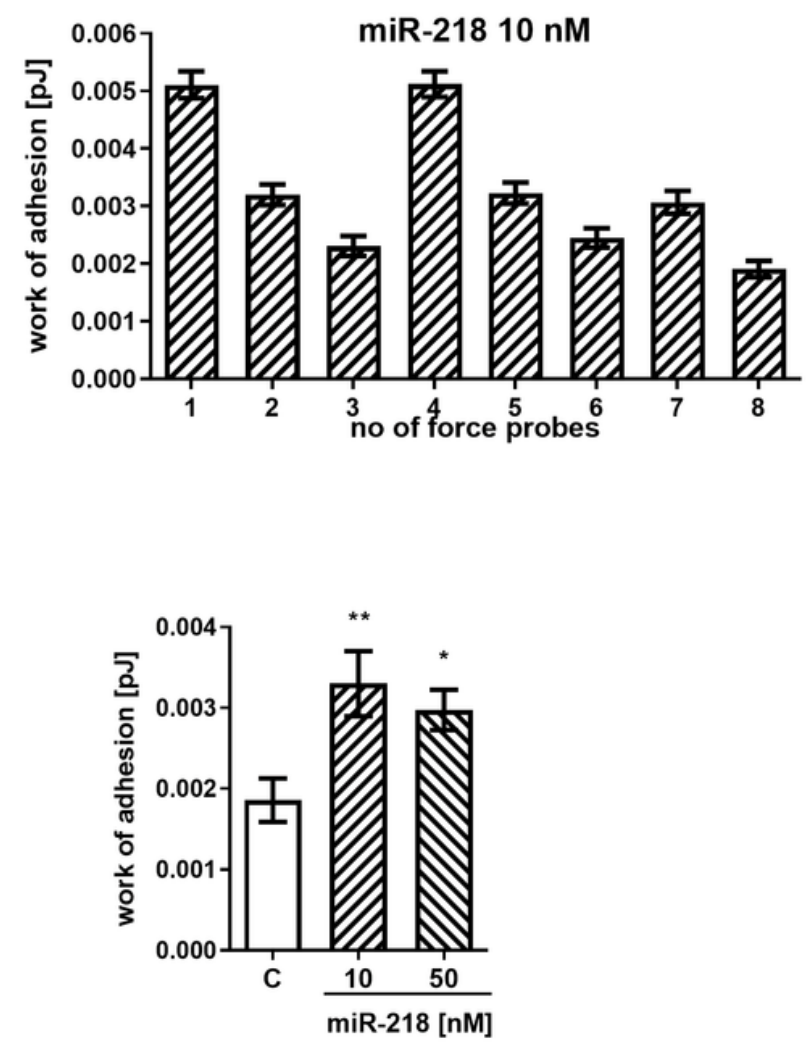

e

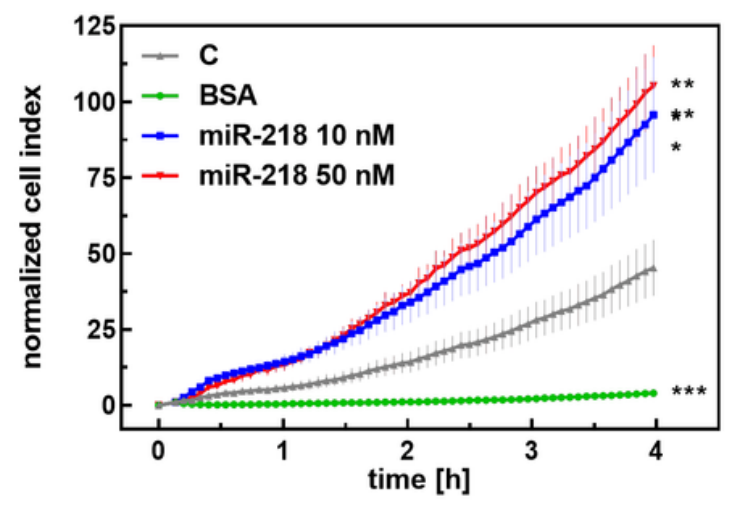

Figure 5

Adhesion of GBM cells increases after miR-218 treatment. The adhesive properties of U-118 MG cells were quantified by SCFS using single cells as force probes. Data for control cells (a), cells transfected with the miR-218 mimic at concentrations of $10 \mathrm{nM}(\mathrm{b})$ and $50 \mathrm{nM}(\mathrm{c})$, and the average result over all measurements (d). (e) Real-time adhesion measured with the xCELLigence system. The graph shows the final impedance values minus the initial values for the corresponding samples. Cells suspended in bovine serum albumin (BSA) were used as the positive control. Data are shown as the mean \pm SD values. Oneway ANOVA, post hoc Bonferroni test; ${ }^{*} p<0.05,{ }^{* \star} p<0.01, * \star * p<0.001$. 
a

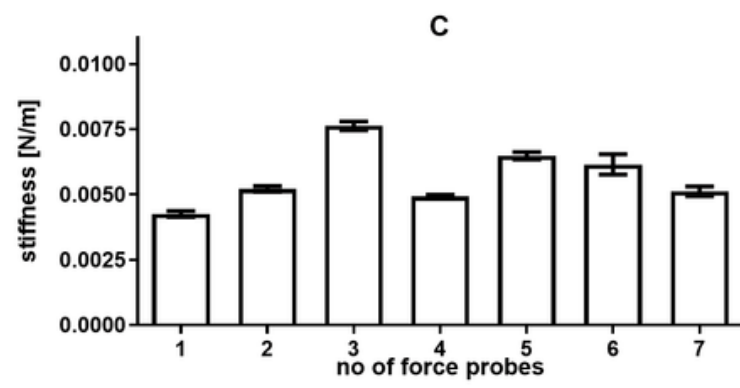

\section{$\mathbf{e}$}

b

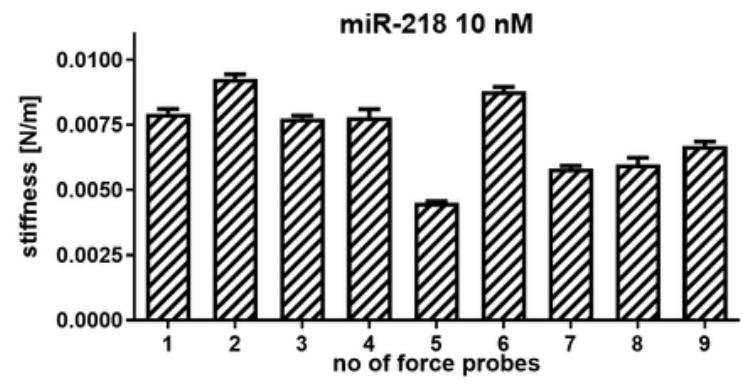

C

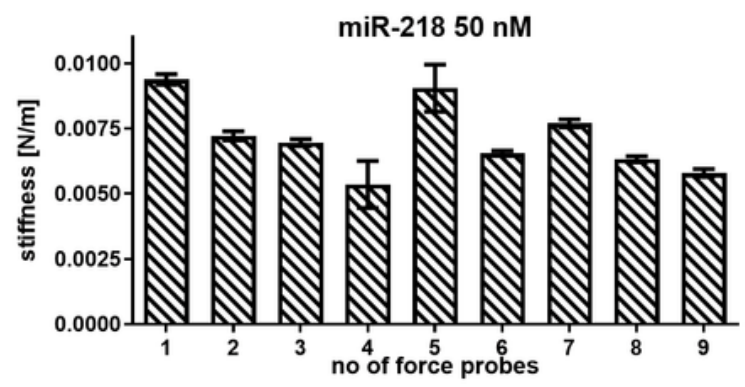

d
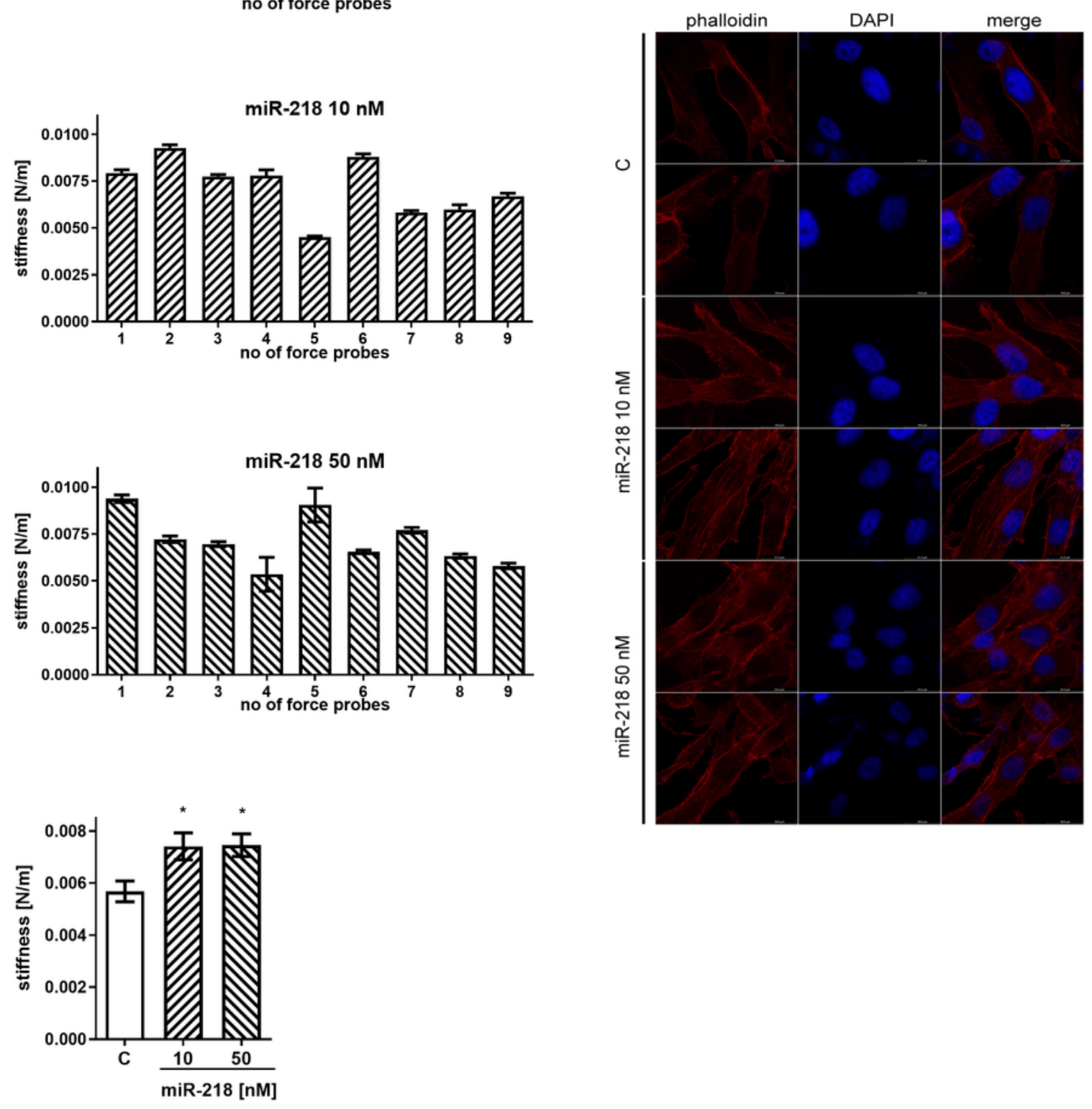

\section{Figure 6}

The mechanical properties of GBM cells after miR-218 treatment. Stiffness of U-118 MG cells quantified based on AFM elasticity measurements and expressed in N/m. Data for control cells (a), cells transfected with the miR-218 mimic at a $10 \mathrm{nM}$ concentration (b) and a $50 \mathrm{nM}$ concentration (c), and the average result over all measurements (d). (e) Confocal imaging of the actin cortex. Phalloidin (red) and DAPI 
(blue) staining was performed to visualize actin fibres and cell nuclei, respectively. Z-stack images were acquired. Data are shown as the mean \pm SD values. One-way ANOVA, post hoc Bonferroni test, * $p<0.05$.

\section{Supplementary Files}

This is a list of supplementary files associated with this preprint. Click to download.

- Supplementaryinformation1.xlsx 